\title{
A Facile and Effective Method to Improve the Dispersibility of WS2 Nanosheets in PAO8 for the Tribological Performances
}

\section{DOI:}

10.1016/j.triboint.2017.09.012

\section{Document Version}

Accepted author manuscript

Link to publication record in Manchester Research Explorer

Citation for published version (APA):

Zhang, R., Qiao, D., Liu, X., Guo, Z., Cai, M., \& Shi, L. (2018). A Facile and Effective Method to Improve the Dispersibility of WS Nanosheets in PAO8 for the Tribological Performances. Tribology International, 118, 60-70. https://doi.org/10.1046/j.triboint.2017.09.012

\section{Published in:}

Tribology International

\section{Citing this paper}

Please note that where the full-text provided on Manchester Research Explorer is the Author Accepted Manuscript or Proof version this may differ from the final Published version. If citing, it is advised that you check and use the publisher's definitive version.

\section{General rights}

Copyright and moral rights for the publications made accessible in the Research Explorer are retained by the authors and/or other copyright owners and it is a condition of accessing publications that users recognise and abide by the legal requirements associated with these rights.

\section{Takedown policy}

If you believe that this document breaches copyright please refer to the University of Manchester's Takedown Procedures [http://man.ac.uk/04Y6Bo] or contact uml.scholarlycommunications@manchester.ac.uk providing relevant details, so we can investigate your claim.

\section{OPEN ACCESS}


International

Elsevier Editorial System(tm) for Tribology

Manuscript Draft

Manuscript Number: TRIBINT-D-17-00970R1

Title: A Facile and Effective Method to Improve the Dispersibility of WS2 Nanosheets in PAO8 for the Tribological Performances

Article Type: Full Length Article

Keywords: dispersibility

WS2 nanosheets

tribological performance

lubricating mechanism

Corresponding Author: Dr. lei shi, Ph.D

Corresponding Author's Institution: Licp

First Author: ruochong zhang, Master

Order of Authors: ruochong zhang, Master; dan qiao; xuqing liu; zhiguang guo; meirong cai; lei shi, Ph.D

Abstract: The sedimentation of WS2 nanosheets in PAO8 is resolved by a facile method with the immobilization function of 1-methyl-2, 4-bis (Noctadecylurea) benzene (MOB), and tribological performance and mechanism of the composite lubricant are systematically investigated. Compared with blank PAO8, the composite lubricants have better tribological performance, which is attributed to the synergistic effect of WS2 and $\mathrm{MOB}$. The immobilization function of MOB because of the network structure prevents the agglomeration and sedimentation of WS2 nanosheets. The boundary films, including tribochemical reaction film and physical absorbing film are formed on the surfaces of the friction pair during the friction process. 
Dear editor,

Here we would like to submit our enclosed original research article entitled "A Facile and Effective Method to Improve the Dispersibility of $\mathrm{WS}_{2}$ Nanosheets in PAO8 for the Tribological Performances", which we would like to be considered for publication in Tribology International.

The authors: Ruochong Zhang, Dan Qiao, Xuqing Liu, Zhiguang Guo, Meirong Cai, Lei Shi

In the present paper, a facile and novel method has been proposed to resolve the agglomeration problem of $\mathrm{WS}_{2}$ nanosheets in the PAO8 by utilizing the immobilization function of 1-methyl-2, 4-bis (N-octadecylurea) benzene (MOB). The results show that the excellent tribological performances are attributed to the synergistic effect of $\mathrm{WS}_{2}$ nanosheets and MOB. The immobilization function of MOB promotes $\mathrm{WS}_{2}$ nanosheets to disperse uniformity in PAO8 and reach the full potential in lubricating properties. The boundary lubricating film, containing tribochemical film and physical absorbing film are formed to avoid the direct contact of friction pair. The combined actions of $\mathrm{WS}_{2}$ nanosheets and MOB give the contribution to the admirable lubricating properties of the composite lubricant.

We confirm that this manuscript has not been published elsewhere and is not under consideration by another journal. All authors have approved the manuscript and agree with submission to Tribology International. The study was supported by a grant from the National Natural Science Foundation of China (51405477, 51675512). The authors have no conflicts of interest to declare. 
We look forward to hearing from you at your earliest convenience.

Sincerely yours,

Lei Shi

\section{Corresponding authors:}

\section{Lei Shi,}

E-mail: leishi@licp.cas.cn

Tel: +(86)931-4968177

Addr. : State Key Laboratory of Solid Lubrication, Lanzhou Institute of Chemical Physics, Chinese Academy of Sciences, Tianshui Middle Rd 18, Lanzhou 730000, P. R. China.

Meirong Cai:

E-mail: caimr@licp.cas.cn

Tel: +(86)931-4968079

Addr. : State Key Laboratory of Solid Lubrication, Lanzhou Institute of Chemical Physics, Chinese Academy of Sciences, Tianshui Middle Rd 18, Lanzhou 730000, P. R. China. 
Dear Editor,

1. The work described here has not been submitted elsewhere for publication, and all the authors listed have approved the manuscript that is enclosed.

2. I have read and have abided by the statement of ethical standards for manuscripts submitted to Tribology International.

Thanks very much for your attention to our paper.

Sincerely Yours,

Lei Shi 


\section{Highlights}

- The good dispersibility of nanomaterial in base oil was obtained by a facile and effective method.

- The immobilization function of $\mathrm{MOB}$ on $\mathrm{WS}_{2}$ nanosheets in base oil is proved.

- The synergistic effect of $\mathrm{WS}_{2}$ nanosheets and MOB on lubricating performance is demonstrated in the paper.

- The lubrication mechanisms of the composite lubricant, containing immobilization function of $\mathrm{MOB}$ and formation of boundary film were investigated systematically. 
Dear Prof. Weimin Liu,

Thanks very much for your email regarding our manuscript again (Ms. Ref. No.: TRIBINT-D-17-00970). We should show our appreciations to you again for your consideration for our manuscript. As for this question proposed by the reviewers and editor, we have carefully checked the whole manuscript again and changed the manuscript according to the referee's comments. Meanwhile, we have further polished the English throughout the manuscript. Some data has been supplemented and perfected to complete the manuscript. The manuscript with and without the revised track are both provided.

Yours sincerely,

Lei Shi

\section{Detailed responses to the comments made by the Editor are listed as follows:}

Reviewer \#2:

1) What is the real composition of these boundary layers resulting from the physical absorption and tribochemical lubrication?

Thanks very much for your question. According to the data of XPS and Raman spectra analysis (Fig.11 and 12, Table 2), not only could MOB and $\mathrm{WS}_{2}$ nanosheets as additives in PAO8 complicate tribochemical reactions occur, leading to a surface protective film composed of sulphur oxides, organic sulfides, nitrogen oxide, nitrates and iron oxides on the lubricated metal surface, but physical adsorption film of $\mathrm{WS}_{2}$ nanosheets also formed. This boundary protective layer benefits friction reduction and anti-wear preformances. 
(a)

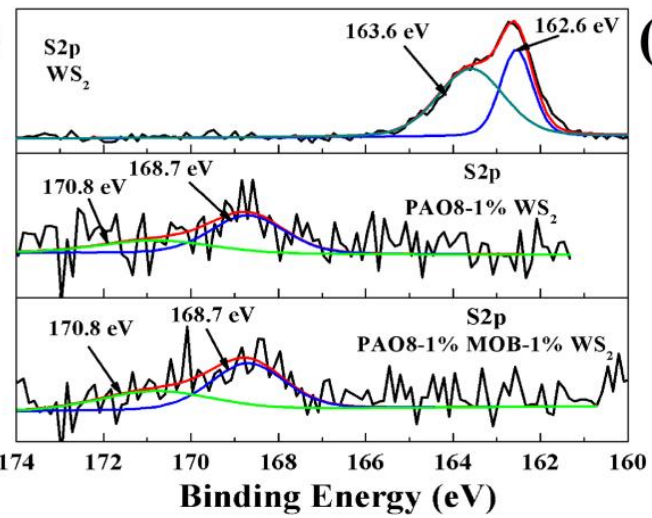

(c)

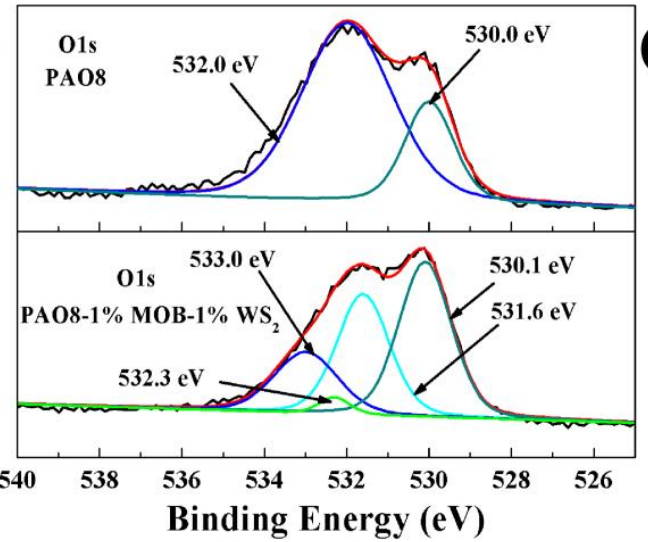

(b)

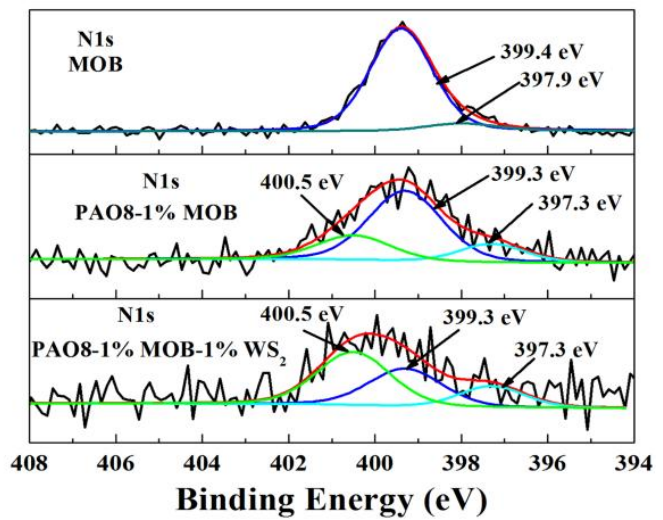

(d)

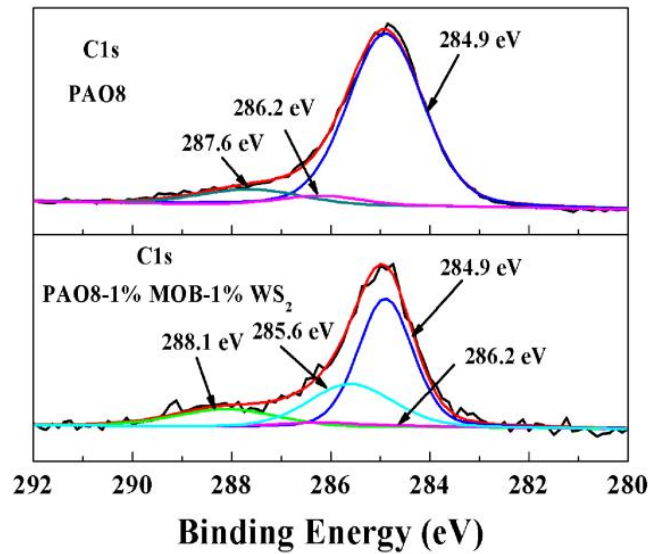

Fig. 11 XPS spectra of S2p, N1s, O1s, C1s of MOB, $\mathrm{WS}_{2}$ and the worn scars lubricated by the different lubricants.

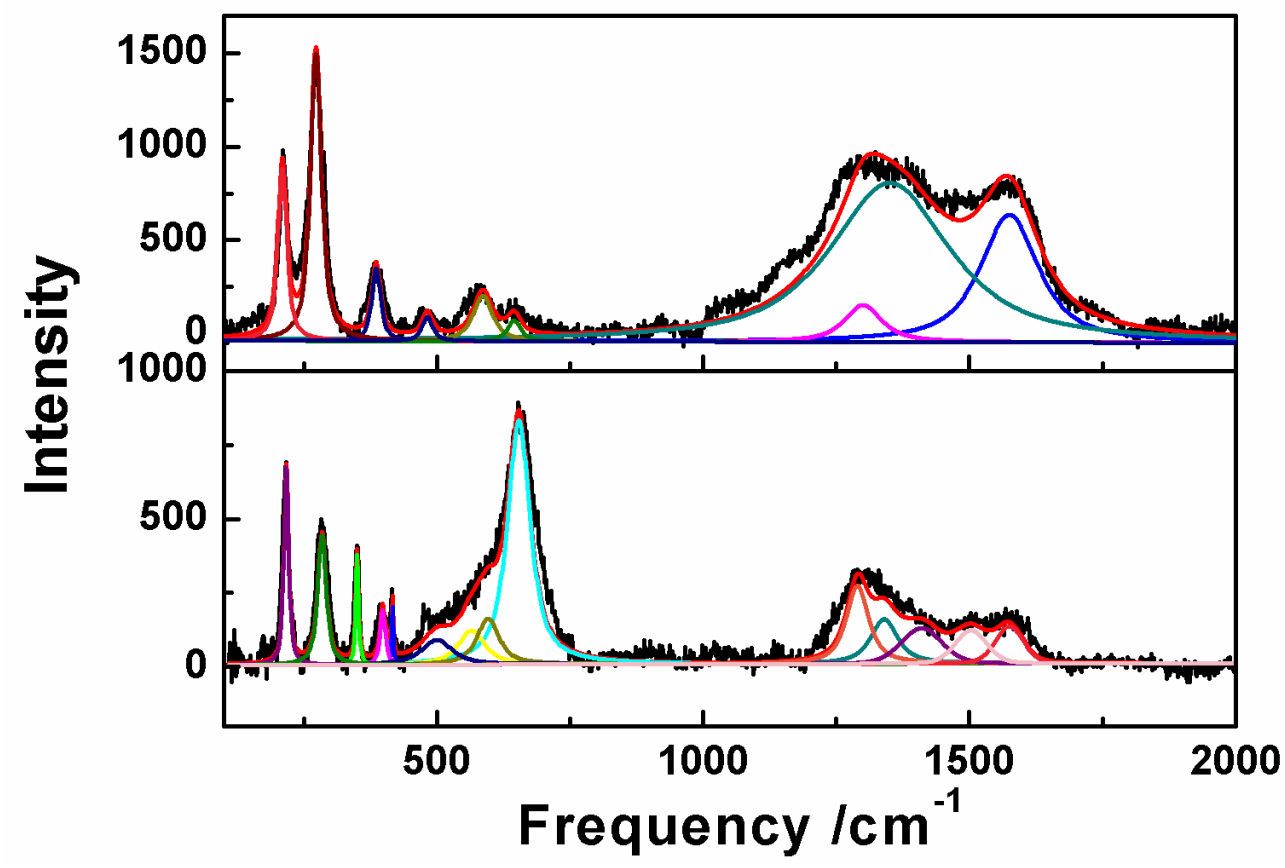

Fig. 12 Raman spectra of the wear scars lubricated by (a) PAO8 and (b) PAO8-1\% MOB-1\% $\mathrm{WS}_{2}$. 
Table 2. Identification of peaks of Raman spectra about wear scars lubricated by PAO8 and

PAO8-1\% MOB-1\% $\mathrm{WS}_{2}$ under frequency ramp test.

\begin{tabular}{|c|c|c|c|}
\hline \multicolumn{2}{|r|}{ PAO8 } & \multicolumn{2}{|c|}{ PAO8-1\% MOB- $1 \% \mathrm{WS}_{2}$} \\
\hline Frequency $/ \mathrm{cm}^{-1}$ & Corresponding compounds & Frequency $/ \mathrm{cm}^{-1}$ & Corresponding compounds \\
\hline 210 & $\alpha-\mathrm{Fe}_{2} \mathrm{O}_{3}[46-47]$ & $217,184,500$ & $\alpha-\mathrm{Fe}_{2} \mathrm{O}_{3}[46-47]$ \\
\hline 273 & $\alpha-\mathrm{Fe}_{2} \mathrm{O}_{3}$ [46-47] & 350,417 & $\mathrm{WS}_{2}[28]$ \\
\hline 386 & $\gamma$-FeOOH $[46,48]$ & 398 & S-C-C deformation vibration [50] \\
\hline 482 & $\alpha-\mathrm{FeOOH}[46]$ & 565 & Fe-N-O binding vibration [49] \\
\hline 586 & $\alpha-\mathrm{Fe}_{2} \mathrm{O}_{3}, \mathrm{Fe}-\mathrm{C}-\mathrm{O}[46-47,49]$ & 596 & Fe-NO stretching vibration [49] \\
\hline 645 & $\mathrm{Fe}_{3} \mathrm{O}_{4}[46]$ & 654 & $\mathrm{~S}-\mathrm{CH}_{2}$ stretching vibration [50] \\
\hline 1300 & $\gamma$-FeOOH $[46,48]$ & 1290 & $\begin{array}{c}\text { C-N stretching vibration of } \\
\text { Aromatic amine [18] }\end{array}$ \\
\hline & & & $\mathrm{N}=\mathrm{N}$ stretching vibration of the \\
\hline 1340 & Carbonization [44-45] & 1410 & $\begin{array}{l}\text { azo compound conjugated to the } \\
\text { aromatic ring [18] }\end{array}$ \\
\hline 1575 & Carbonization [44-45] & 1503 & NH in-plane bending vibration [51] \\
\hline-- & -- & 1340,1575 & Carbonization [44-45] \\
\hline
\end{tabular}

2) What is the reason that these boundary layers are remaining stable for the best performance?

Thanks very much for your question. There are several reasons for the boundary layers to remain stable for the best performance: first, the immobilization performance of MOB promotes the dispersibility of $\mathrm{WS}_{2}$ nanosheets in PAO8; second, $\mathrm{WS}_{2}$ nanosheets immobilized in the network of $\mathrm{MOB}$ are gradually released on the friction surface, so PAO8-MOB-WS 2 presents the better long-term lubricating performance than $\mathrm{PAO} 8 \mathrm{-MOB}$ and $\mathrm{PAO} 8-\mathrm{WS}_{2}$; third, the active elements in MOB molecules and $\mathrm{WS}_{2}$ nanosheets easily react with steel surfaces to produce the stable tribochemical reaction film; finally, the layer structure of $\mathrm{WS}_{2}$ help $\mathrm{WS}_{2}$ to form the stable and long-term effective physical absorption film on the surfaces of the friction pairs.

3) Some figures such as 3a, 3b, 4 and even 8 and 9 are not necessary in the manuscript and can be deleted from the proposed manuscipt and the corresponding description as to be adopted accordingly.

Thanks very much for your suggestion. In the present work, the excellent 
dispersibility and stability of $\mathrm{WS}_{2}$ nanosheets in PAO8 is obtained and proved by the digital picture in Figure 3. And Figure 8 could demonstrate morphology of wear scars, helping to further understand the tribological process and lubricating mechanism. Therefore, we consider the Figure 3 and Figure 8 are too necessary to delete in the work. According to the suggestion, Figure 4 and Figure 9 were deleted and the corresponding description was adjusted.

Reviewer \#3:

1) Introduction part must be rewrite taking care of language and completeness of sentences.

Thanks very much for your suggestion. We have rewritten the introduction according to your opinions. We hope that this introduction can satisfy the request.

2) Authors didn't provide the testing standards which they have been used in their studies.

Thanks very much for your suggestion. We think the testing standards you mentioned are that of friction tests. The testing conditions chosen in the present work are according to the previous researches and our experimental experience rather than testing standard. The details could be obtained according to following reference:

(1) Yu QL, Fan MJ, Li DM, Song ZH, Cai MR, Zhou F and Liu WM. Thermoreversible gel lubricants through universal supramolecular assembly of a nonionic surfactant in a variety of base lubricating liquids. ACS Appl Mater Inter 2014; 6: 15783-94.

(2) Huang GW, Yu QL, Ma ZF, Cai MR and Liu WM. Probing the lubricating mechanism of oil-soluble ionic liquids additives. Tribol Int 2017; 107: 152-62.

(3) Han Yunyan, Qiao Dan, Guo Yuexia and Feng Dapeng. Tribological performance and mechanism of phosphonate ionic liquids as additives in two hydrocarbon oils. Tribol 2017; 37:27-34.

3) Authors have used to demonstrate the stability of nanofluids only by sedimentation. Besides this, authors have to use UV-Visible spectroscopy to strengthen their statement.

Thanks very much for your suggestion. The stabilities of PAO8-1\% $\mathrm{WS}_{2}$ and PAO8-1\% MOB-1\% $\mathrm{WS}_{2}$ were demonstrated by UV-Visible spectroscopy in Fig. 4 in the manuscript and the paper has been modified as "The transmittance of PAO8-1\% $\mathrm{WS}_{2}$ and PAO8-1\% MOB-1\% $\mathrm{WS}_{2}$ were investigated by UV-Visible spectroscopy in Fig. 4 to further record the stability of the both lubricants. It shows that the transmittance values of the two lubricants are zero for homogeneous dispersion of $\mathrm{WS}_{2}$ nanosheets in PAO8 oil at the beginning of the test. However, the transmittance value of PAO8-1\% $\mathrm{WS}_{2}$ increases to about $30 \%$ after $24 \mathrm{~h}$ standing and $60 \%$ after $48 \mathrm{~h}$ standing, showing the apparent agglomeration and sendimentation tendency. The transmittance value of PAO8-1\% $\mathrm{WS}_{2}$ reaches to nearly $80 \%$ after 9 days while that of PAO8-1\% MOB-1\% $\mathrm{WS}_{2}$ maintaines 0 during the whole process. The results combining that of the above sedimentation experience in Fig. 3 both indicate the excellent stability of gel lubricant." 

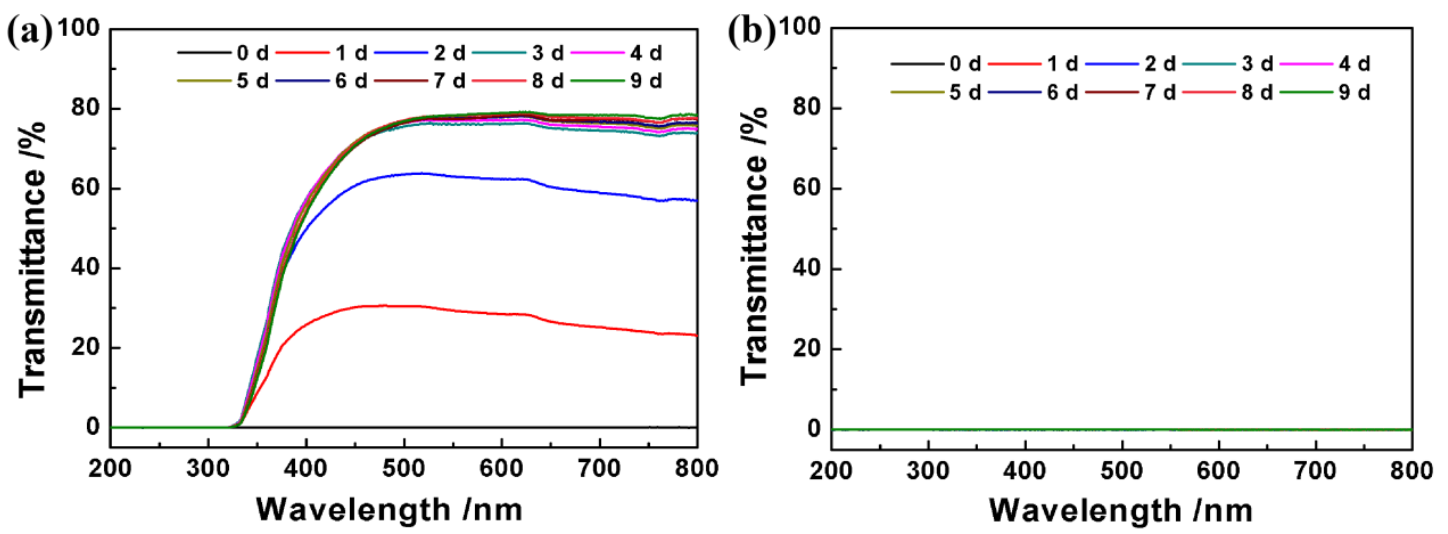

Fig. 4 The transmittance of (a) PAO- $1 \% \mathrm{WS}_{2}$ and (b) PAO8-1\% MOB-1\% $\mathrm{WS}_{2}$ recorded by

UV-Visible spectroscopy with the evolution of time.

4) The manuscript needs some data in commercial formulations (like 5W30, 10W40) to demonstrate their true potentials.

Thanks very much for your suggestion. Some relevant data have been provided in the Fig. 9 in the manuscript and the paper has been modified as "Figure $9 \mathrm{a}$ and $9 \mathrm{~b}$ show the picture of $5 \mathrm{~W} 30-1 \% \mathrm{MOB}$ and $5 \mathrm{~W} 30-1 \% \mathrm{MOB}-1 \% \mathrm{WS}_{2}$, which indicating the excellent gelation ability of MOB in PAO8 and PAO8 with $\mathrm{WS}_{2}$ nanosheets. The tribological performances of $\mathrm{MOB}$ and $\mathrm{WS}_{2}$ nanosheets in $5 \mathrm{~W} 30$ were replenished in Fig. 9c and 9d of the manuscript to illustrate the potential applications of the both additives in the commercial oil. It shows that the COF and wear volume values of $5 \mathrm{~W} 30$ decrease after the addition of $1 \% \mathrm{MOB}$ and $1 \% \mathrm{WS}_{2}$. The wear volume value of $5 \mathrm{~W} 30-1 \%$ MOB-1\% $\mathrm{WS}_{2}\left(2 \times 10^{5} \mu \mathrm{m}^{3}\right)$ is lower than

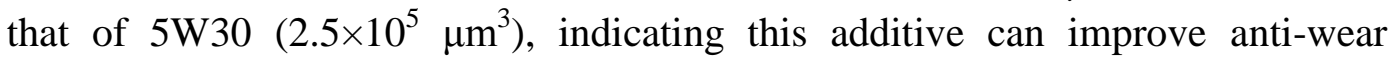
property of the commercial full formula lubricant. Combined the COF curve in Figure 9d, the running-in period of $5 \mathrm{~W} 30$ is alleviated when MOB and $\mathrm{WS}_{2}$ added, showing the certain lubricating advantages of $5 \mathrm{~W} 30-1 \% \mathrm{MOB}-1 \% \mathrm{WS}_{2}$ than that of 5W30 commercial oil."
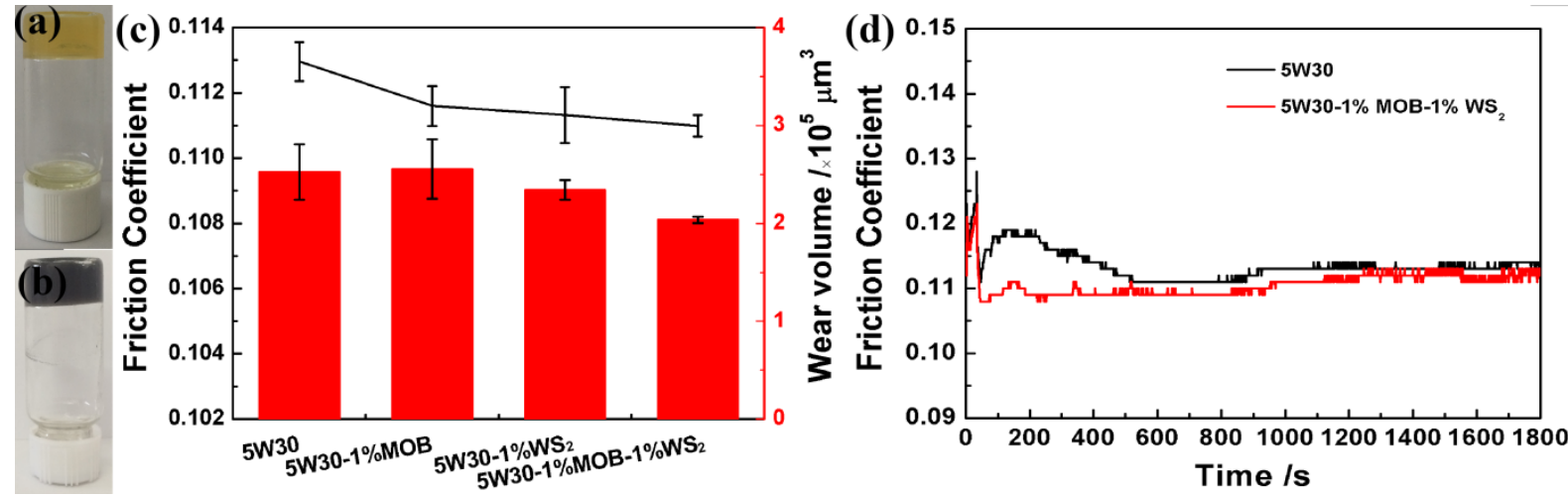

Fig. 9 The picture of (a) 5W30-1\% MOB and (b) 5W30-1\% MOB-1\% $\mathrm{WS}_{2}$ lubricants;

(c) Mean COF and wear volume of 5W30, 5W30-1\% MOB, 5W30-1\% $\mathrm{WS}_{2}$ and 5W30-1\%

MOB-1\% $\mathrm{WS}_{2}$ (d) real-time COF of $5 \mathrm{~W} 30$ and $5 \mathrm{~W} 30-1 \% \mathrm{MOB}-1 \% \mathrm{WS}_{2}$.

\section{5) The survey XPS scan of the lubricated sample must be provided.}

Thanks very much for your suggestion. The survey XPS scans of different lubricants are provided in the follow Figure 2. The peak of S element is hardly to detect in the 
survey spectra for the little content on the wear scar surfaces. However the fine spectra showing in the manuscript are fully demonstrated the existence of S element and the tribochemical reaction of $\mathrm{WS}_{2}$. The corresponding contents of the manuscript are not revised.

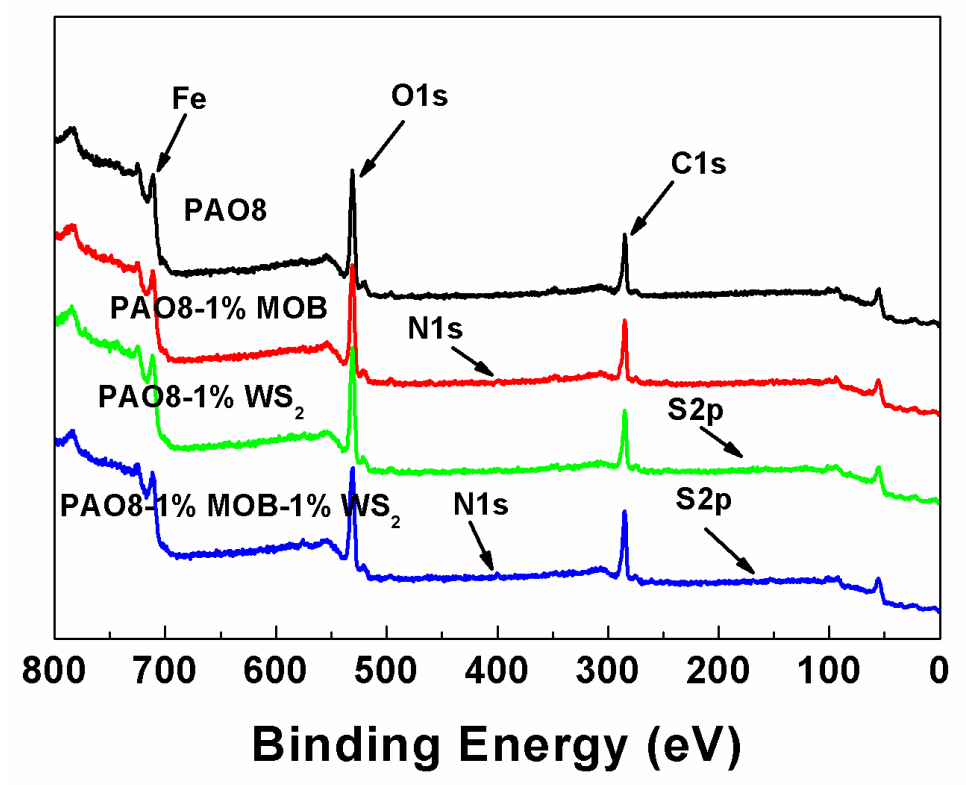

Figure 1. The survey XPS scan of different lubricants

Reviewer \#4:

1) p.2, 1. 9: now is "van der waals" - should be "van der Waals"

Thanks very much for your reminder. The mistake has been corrected in the revised manuscript.

2) p.5, 1.15: please provide clearly, how many repetitions had tribological tests and what statistical function (e.g. standard deviation, confidence intervals) was applied for mean values calculating (e.g. Fig. 5 - COF and wear volume)

Thanks very much for your question. In the present work, three repetitive measurements were performed for each tribological process and the standard deviation was used for mean values calculating. The representative repetitive tests are showed in the following Figure 2. 

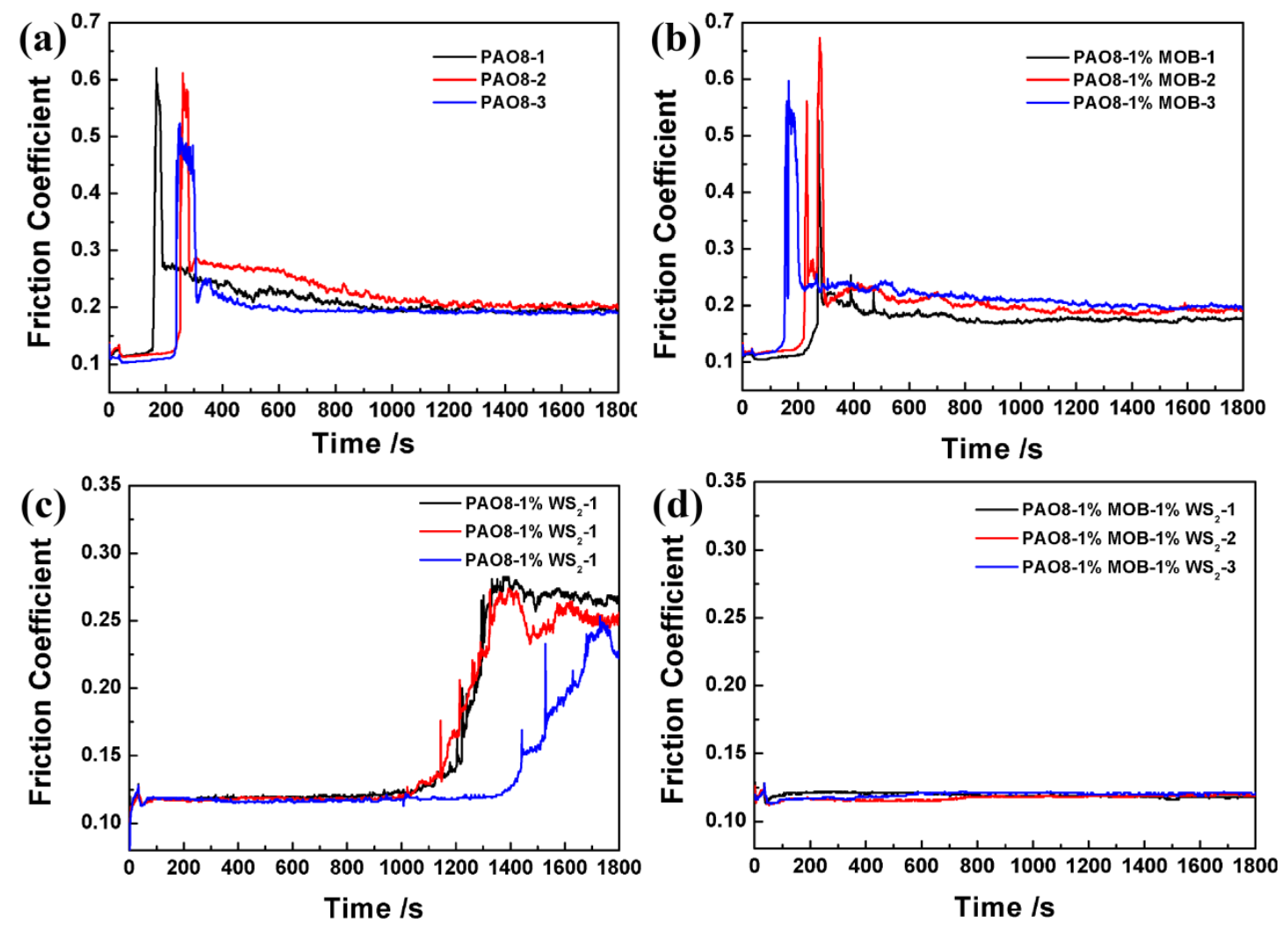

Figure 2 The repetitive tribological tests of (a) PAO8, (b) PAO8-1\% MOB, (c) PAO8-1\% $\mathrm{WS}_{2}$, (d) PAO8-1\%MOB-1\% $\mathrm{WS}_{2}$.

3) authors should present more detailed information concerning the way of wear volume calculation

Thanks very much for your suggestion. The wear volume in the present work is directly calculated by the software of MicroXAM-3D noncontact surface mapping profiler without further processing.

4) Fig. 5a - description - I suppose that the unit of wear volume should be cubic micro-meters

Thanks very much for your reminder. The mistake has been corrected in the revised manuscript.

5) Fig. 6 - why only extreme cases were investigated (PAO8 and PAO8-1\% MOB-1\% $\left.\mathrm{WS}_{2}\right)$ ?

Thanks very much for your question. We have adjusted the orders of Figure 6, 7 and 8 for the better organized article structure. The main purpose of the present work was effectively making full use of the merits of $\mathrm{MOB}$ and $\mathrm{WS}_{2}$ nanosheets to enhance the tribological performance of PAO8. And the synergistic effect of both additives in PAO8 had been investigated, showing that PAO8-1\% MOB-1\% $\mathrm{WS}_{2}$ possess better friction-reducing and anti-wear performance than PAO8-1\% MOB, PAO8-1\% $\mathrm{WS}_{2}$ and PAO8. Then the systematic tribological performances of PAO8 and PAO8-1\% MOB-1\% $\mathrm{WS}_{2}$ were investigated to further evaluate the improvement of lubricating properties.

6) Fig. 6 - how to explain the decrease and stabilization of the COF value in the case 
PAO8? (Even under increasing load - Fig. 6d). We have no here any AW/EP additives which can be activated by temperature (as a consequence of increasing frequency or load).

Thanks very much for your question. As you can see from Fig. 6 in the revised manuscript, the mean COF of the PAO8 lubricant is about 0.2, and the test condition has little influence on the value of COF. These indicate that PAO8 has a stable tribological property. In the initial friction stage in Fig. 8 in the revised manuscript, PAO8 may form boundary lubricating film and the curve shape was stable for the initial 200-300 s. Then the boundary film might be worn away and could not complement rapidly probably because of low absorption strength of PAO8, the COF suddenly increased to 0.5-0.6, and afterward stabilized at the value equal to 0.2 after the running-in period for the re-formation of boundary lubrication film. And the phenomenon has been demonstrated in many researches. The details could be obtained according to following reference:

(1) Yu QL, Fan MJ, Li DM, Song ZH, Cai MR, Zhou F and Liu WM. Thermoreversible gel lubricants through universal supramolecular assembly of a nonionic surfactant in a variety of base lubricating liquids. ACS Appl Mater Inter 2014; 6: 15783-94.

(2) Huang GW, Yu QL, Ma ZF, Cai MR and Liu WM. Probing the lubricating mechanism of oil-soluble ionic liquids additives. Tribol Int 2017; 107: 152-62.

7) p.10, 1.54/55: in my opinion is rather conjecture - there is no clear evidence of this reaction

Thanks very much for your suggestion. The tribochemical reactions of $\mathrm{WS}_{2}$ nanosheets were inferred by the XPS spectra of S2p and Raman spectra. It shows that when lubricated by PAO8-1\% WS 2 and PAO8-1\%MOB-1\% $\mathrm{WS}_{2}$, the peak of $\mathrm{S} 2 \mathrm{p}$ was shifted from $163.6 \mathrm{eV}$ and $162.6 \mathrm{eV}$ to $170.8 \mathrm{eV}$ and $168.7 \mathrm{eV}$, which means that the active element sulfur in $\mathrm{WS}_{2}$ involves in a tribochemical reaction during the friction process. Combined the $\mathrm{O} 1 \mathrm{~s}$ peak at $531.6 \mathrm{eV}, \mathrm{C} 1 \mathrm{~s}$ peak at 285.6 $\mathrm{eV}$ and the new peaks at $168.7 \mathrm{eV}$ and $170.8 \mathrm{eV}$ of $\mathrm{S} 2 \mathrm{p}$, the sulphur oxides and organic sulfides are deduced to be produced when lubricated by PAO8-1\% MOB-1\% $\mathrm{WS}_{2}$ according to the references [30-37] in the manuscript. What's more, the Raman spectra analysis also indicates that the complicated tribochemical reaction occurred during the friction process. The results are showed in the Table 3 of the manuscript. 
(a)

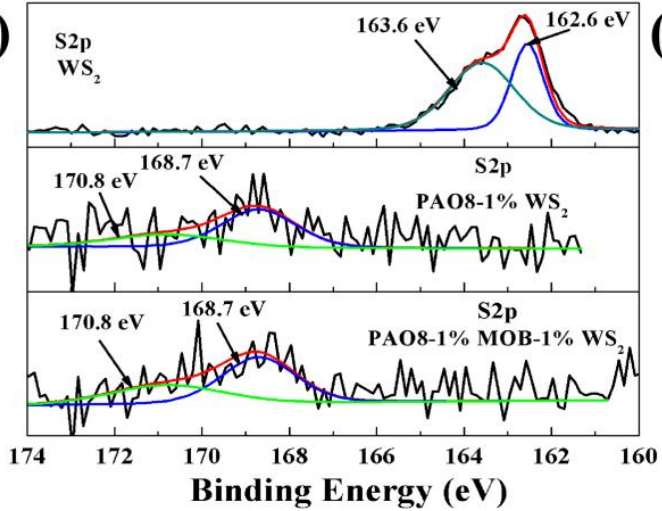

(c)

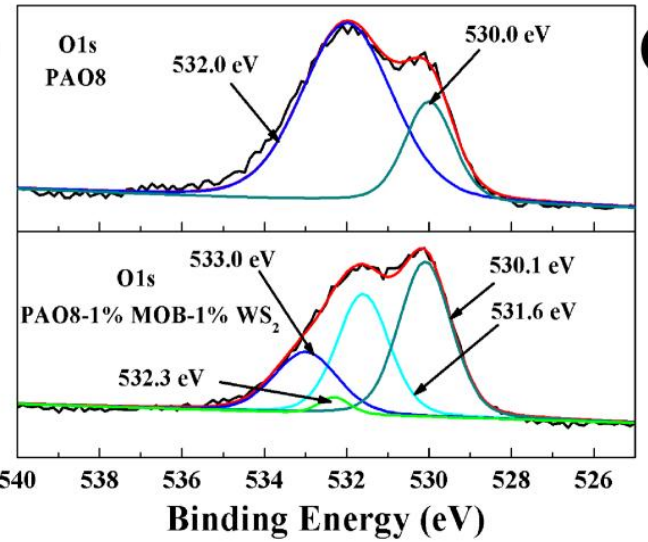

(b)

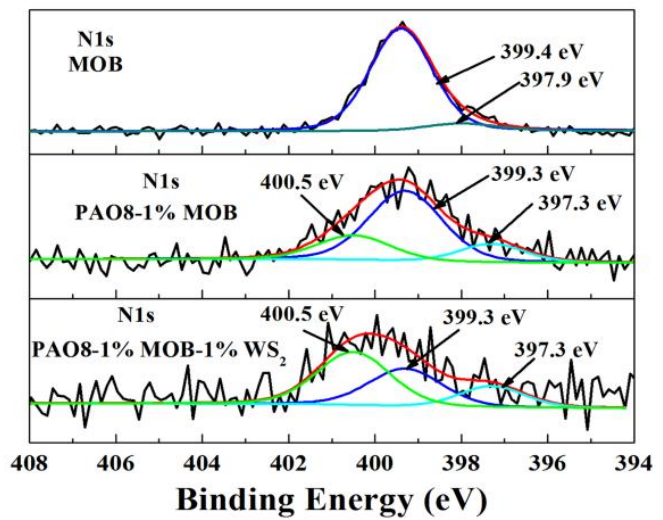

(d)

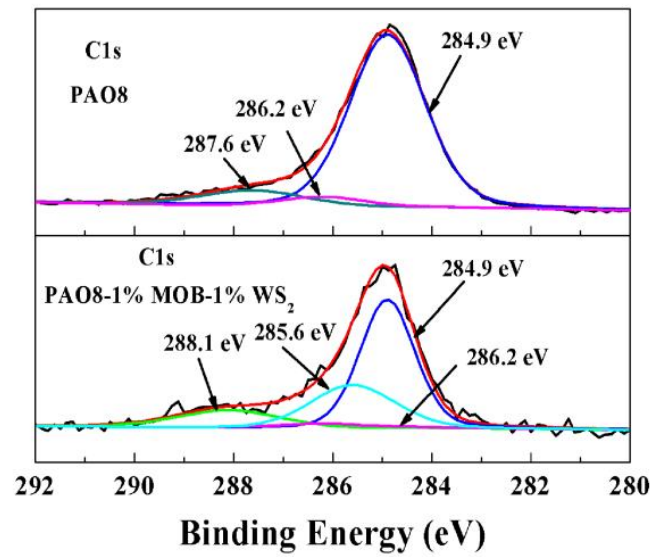

Fig. 11 XPS spectra of S2p, N1s, O1s, C1s of MOB, $\mathrm{WS}_{2}$ and the worn scars lubricated by the different lubricants.

Table 2 Identification of peaks of Raman spectra about wear scars lubricated by PAO8 and PAO8-1\% MOB-1\% $\mathrm{WS}_{2}$ under frequency ramp test

\begin{tabular}{|c|c|c|c|}
\hline \multicolumn{2}{|r|}{ PAO8 } & \multicolumn{2}{|c|}{ PAO8-1\% MOB-1\% $\mathrm{WS}_{2}$} \\
\hline Frequency $/ \mathrm{cm}^{-1}$ & Corresponding compounds & Frequency $/ \mathrm{cm}^{-1}$ & Corresponding compounds \\
\hline 210 & $\alpha-\mathrm{Fe}_{2} \mathrm{O}_{3}[46-47]$ & $217,184,500$ & $\alpha-\mathrm{Fe}_{2} \mathrm{O}_{3}[46-47]$ \\
\hline 273 & $\alpha-\mathrm{Fe}_{2} \mathrm{O}_{3}[46-47]$ & 350,417 & $\mathrm{WS}_{2}[28]$ \\
\hline 386 & $\gamma$-FeOOH $[46,48]$ & 398 & S-C-C deformation vibration [50] \\
\hline 482 & $\alpha-\mathrm{FeOOH}[46]$ & 565 & Fe-N-O binding vibration [49] \\
\hline 586 & $\alpha-\mathrm{Fe}_{2} \mathrm{O}_{3}, \mathrm{Fe}-\mathrm{C}-\mathrm{O}[46-47,49]$ & 596 & Fe-NO stretching vibration [49] \\
\hline 645 & $\mathrm{Fe}_{3} \mathrm{O}_{4}[46]$ & 654 & $\mathrm{~S}-\mathrm{CH}_{2}$ stretching vibration [50] \\
\hline 1300 & $\gamma$-FeOOH $[46,48]$ & 1290 & $\begin{array}{l}\text { C-N stretching vibration of } \\
\text { Aromatic amine [18] }\end{array}$ \\
\hline 1340 & Carbonization [44-45] & 1410 & $\begin{array}{l}\mathrm{N}=\mathrm{N} \text { stretching vibration of the } \\
\text { azo compound conjugated to the }\end{array}$ \\
\hline
\end{tabular}


aromatic ring [18]

30. Choi CL, Feng J, Li YG, Wu J, Zak A, Tenne R, Dai HJ. WS 2 nanoflakes from nanotubes for electrocatalysis. Nano Res 2013;6:921-8.

31. Cheng L, Huang WJ, Gong QF, Liu CH, Liu Z, Li YG, Dai HJ. Ultrathin $\mathrm{WS}_{2}$ nanoflakes as a high-performance electrocatalyst for the hydrogen evolution reaction. Angew Chem Int Edit 2014;53:7860-3.

32. Dozzi MV, Livraghi S, Giamello E, Selli E. Photocatalytic activity of S-and F-doped $\mathrm{TiO}_{2}$ in formic acid mineralization. Photochem Photobiol Sci 2011;10:343-9.

33. Cheng L, Dong SJ. A novel potentiodynamic method of electrochemical growth for layer-by-layer film formation based on electrostatic interaction. Electrochem Commun 1999;1:159-62.

34. Schulze M, Lorenz M, Wagner N, Gülzow E. XPS analysis of the degradation of Nafion. Fresen J Aanal Chem 1999;365:106-13.

35. Duan JX, Yu J, Feng SL, Su L. A rapid microwave synthesis of nitrogen-sulfur co-doped carbon nanodots as highly sensitive and selective fluorescence probes for ascorbic acid. Talanta 2016;153:332-9.

36. Wang YR, Yu QL, Cai MR, Shi L, Zhou F and Liu WM. Synergy of lithium salt and non-ionic surfactant for significantly improved tribological properties of water-based fluids. Tribol Int 2017;113:58-64.

37. http://srdata.nist.gov/xps/ 
A Facile and Effective Method to Improve the Dispersibility of $\mathrm{WS}_{2}$ Nanosheets in PAO8 for the Tribological

\title{
Performances
}

\author{
Ruochong Zhang, ${ }^{\mathrm{a}, \mathrm{b}}$, Dan Qiao ${ }^{\mathrm{a}}$, Xuqing Liu ${ }^{\mathrm{c}}$, Zhiguang Guo ${ }^{\mathrm{a}, \mathrm{d}}$, \\ Meirong Cai ${ }^{\mathrm{a}^{*}}$ and Lei Shi ${ }^{\mathrm{a}^{*}}$ \\ ${ }^{a}$ State Key Laboratory of Solid Lubrication, Lanzhou Institute of Chemical Physics, \\ Chinese Academy of Sciences, Lanzhou 730000, China \\ ${ }^{\mathrm{b}}$ University of Chinese Academy of Sciences, Beijing 100049, China \\ ${ }^{c}$ School of Materials, University of Manchester, Oxford Road, Manchester, UK M13 \\ 9PL \\ ${ }^{\mathrm{d}}$ Hubei Collaborative Innovation Centre for Advanced Organic Chemical Materials \\ and Ministry of Education Key Laboratory for the Green Preparation and Application \\ of Functional Materials, Hubei University, Wuhan 430062, China
}

\begin{abstract}
The sedimentation of $\mathrm{WS}_{2}$ nanosheets in PAO8 is resolved by a facile method with the immobilization function of 1-methyl-2, 4-bis (N-octadecylurea) benzene (MOB), and tribological performances and mechanism of the composite lubricant are systematically investigated. Compared with blank PAO8, the composite lubricants have excellent tribological performance, which is attributed to the synergistic effect of $\mathrm{WS}_{2}$ and MOB. The immobilization function of MOB because of the network structure prevents the agglomeration and sedimentation of $\mathrm{WS}_{2}$ nanosheets. The boundary films, including tribochemical reaction film and physical absorbing film are formed on the surfaces of the friction pair during the friction process.

Keywords: dispersibility, $\mathrm{WS}_{2}$ nanosheets, tribological performance, lubricating mechanism
\end{abstract}

\footnotetext{
* Corresponding authors at: State Key Laboratory of Solid Lubrication, Lanzhou Institute of Chemical Physics, Chinese Academy of Sciences, Lanzhou 730000, PR China. E-mail addresses: leishi@licp.cas.cn (L. Shi), caimr@licp.cas.cn (M. Cai)
} 


\section{Introduction}

Some layer materials, such as graphene, $\mathrm{MoS}_{2}$ and $\mathrm{WS}_{2}$, are generally used as the additives of solid and fluid lubricants because of the lower tangential resistance deriving from the van der Waals force among interlayer [1]. And $\mathrm{WS}_{2}$ nanoparticles as the additive in oil and grease show excellent tribological performance under the severe condition. It was found that a small amount of fullerene-like $\mathrm{WS}_{2}$ nanoparticles (IF-WS $)_{2}$ added into the oil can alleviate the friction-coefficient-and wear-volume remarkably as well as improve the load-bearing capacity of the friction pair [2]. Joly-Pottuz investigated the tribological performance of IF- $\mathrm{WS}_{2}$ as additive in oil under boundary lubrication and several theories were proposed to explain the friction reducing properties. The dramatic lubrication performance of $\mathrm{WS}_{2}$ is due to the easy slide among the interlayers and the formation of the transfer film on the surface of friction pair [3]. Rapoport proposed the excellent tribological performances of IF-WS 2 are attributed to the third body material transfer, which is the mixture of oil, $\mathrm{WS}_{2}$ and wear debris [4].

On the strength of thermodynamic argument, Tolman presented that the surface energy could decrease with the decrease of the particle size [5]. And the large surface energy of nanoparticle leads to the agglomeration of particle [6]. The lubricating properties of nano materials would be affected by the agglomeration tendency of nanoparticles, leading to the higher value of friction coefficient and surface worn of friction pairs [7]. At present, three major methods have been applied to improve the dispersibility of nano materials and give full play to their potential: stirring, ultrasonic treatment and chemical modification [8-9]. Moshkovith' study showed that the agglomeration of IF-WS 2 nanoparticle had a dramatic effect on the friction and stirring was an effective method to enhance the dispersibility IF-WS $\mathrm{S}_{2}$ nanoparticles [10]. In fact, it is very difficult to use the continuous stirring and ultrasonic in the lubricating system of moving parts during the practical application. Jiang et al. studied that the ultrathin $\mathrm{WS}_{2}$ nanosheets modified by oleylamine as the additive in poly alpha olefin (PAO6), presented the good dispersion stability during 6 months and the 
admirable lubricating performance over the wide temperature range [11]. However, the strict reaction conditions with high temperature $\left(500{ }^{\circ} \mathrm{C}\right)$ and inert environment (Ar) restrict the broad application.

According to the previous report, the low molecular weight organic gelator (LMWG) as the additive can effectively trap the base oil to improve the tribological performance and prevent the leakage of lubricant [12]. 1-methyl-2, 4-bis (N-octadecylurea) benzene (MOB) as LMWG with ureido (NH-CO-NH) shows the stronger capacity for gelating the solvent with the comparatively low content [13] and excellent tribological performance due to containing the active element $\mathrm{N}$ in ureido [14]. Utilizing the quick gelation ability of MOB, the nano materials in base oil are trapped in the network of MOB before the agglomeration and sedimentation, obtaining the good dispersibility in base oil. However, few have been reported on the incorporation of LMWG and nanoparticles in base oil. In the present work, PAO8 oil with the addition of $\mathrm{WS}_{2}$ nanosheets was immobilized by MOB under a facile condition and the tribological properties and wear mechanisms of the MOB and $\mathrm{WS}_{2}$ as the additive in PAO8 were investigated.

\section{Experimental Section}

\subsection{Materials}

Toluene-2, 4-diisocyanate (TDI) was purchased from Shanghai Sanyou Chemical Reagent Co. Ltd. Octadecylamine (OA) was purchased from Tianjin Guangfu Fine Chemical Research Institute. Absolute ethanol was purchased from Rionlon Bohua (Tianjin) Pharmaceutical \& Chemical Co. Ltd. $\mathrm{WS}_{2}$ nanosheets were purchased from Huajing Powdery Material Science\&Technological Co. Ltd. PAO8 was synthesized according to the previous report [15]. All the other chemicals used in the work were of AR grade and the deionized water was used in all the experiment.

\subsection{Preparation of $M O B$}

MOB was synthesized according to previous research [16]. Briefly, $1.7 \mathrm{~g}$ (10 mmol) TDI with $100 \mathrm{~mL}$ toluene was added to toluene solvent with $5.4 \mathrm{~g}$ (20 mmol) OA under the ice bath condition. Toluene was removed by distillation under reduced pressure after stirring the system for half an hour. The product was refluxed with 
absolute ethanol for half an hour to remove the remaining reactants. This procedure was repeated several times and the white product was dried $12 \mathrm{~h}$ in vacuum oven at 50 ${ }^{\circ} \mathrm{C}$ after filtrating.

\subsection{Preparation of xerogel}

The xerogel was prepared according to previous report [16]. Chlorobenzene with 3\% MOB was heated and stirred to form transparent solution and then slowly cooled to the room temperature (RT). The xerogel of chlorobenzene gel was formed in freeze dryer after removing the chlorobenzene in the network of MOB.

\subsection{Preparation of lubricant}

The system of PAO8 with MOB or $\mathrm{WS}_{2}$ is denoted as PAO8-MOB or PAO8- $\mathrm{WS}_{2}$ and PAO8 with both $\mathrm{MOB}$ and $\mathrm{WS}_{2}$ nanosheets is written as PAO8-MOB-WS ${ }_{2}$. The percentage content mentioned in this paper refers to the mass concentration.

PAO8-MOB- $\mathrm{WS}_{2}: \mathrm{WS}_{2}$ nanosheets were dispersed in PAO8 at a given concentration by stirring for $1 \mathrm{~h}$ and ultrasonic treatment for $15 \mathrm{~min}$ in a sample vessal. A given certain content of MOB were immediately added and dissolved into $\mathrm{PAO} 8$ with $\mathrm{WS}_{2}$ nanosheets by heating and stirring at $140{ }^{\circ} \mathrm{C}$ for $5 \mathrm{~min}$ and then the gel lubricants were formed in several minutes when mixed solution were slowly cooled to the RT. In order to achieve the long-term stability of PAO8-MOB-WS ${ }_{2}$, the concentration of $\mathrm{MOB}$ was chosen as $1 \%$ although the minimum gelator content of $\mathrm{MOB}$ for $\mathrm{PAO} 8-\mathrm{WS}_{2}$ is $0.5 \%$

PAO8- $\mathrm{WS}_{2}: \mathrm{WS}_{2}$ nanosheets were dispersed in PAO8 at a given concentration by stirring for $1 \mathrm{~h}$ and ultrasonic treatment for $15 \mathrm{~min}$ in a sample vessal. It is used immediately after ultrasonic to keep the dispersibility and stability of $\mathrm{WS}_{2}$ nanosheets in oil.

PAO8-MOB: A given content of MOB were added into PAO8 to dissolved in base oil by heating and stirring at $140{ }^{\circ} \mathrm{C}$ for $5 \mathrm{~min}$ and then gel lubricants were formed in several minutes when mixed solution were slowly cooled to the RT.

\subsection{Characteristics}

The structure of MOB was confirmed by Nicolet iS10 FTIR spectrometer and 
LabRAM HR Evolution Raman. The morphology of MOB xerogel and purchased $\mathrm{WS}_{2}$ nanosheets were recorded by Field emission scanning electron microscopy (FESEM, JEOL JSM-6701F). The structure of $\mathrm{WS}_{2}$ was investigated by Raman and X'PERT PRO XRD. The stabilities of PAO8-1\% $\mathrm{WS}_{2}$ and PAO8-1\% MOB-1\% $\mathrm{WS}_{2}$ were studied by Agilent Technologies Cary 60 UV-Visible spectroscopy and sedimentation test. STA 449 C Jupiter simultaneous TG DSC was used to investigate the thermal property of composite lubricant from $25^{\circ} \mathrm{C}$ to $800^{\circ} \mathrm{C}$ with $10^{\circ} \mathrm{C}$ min $^{-1}$ of the temperature ramp under air.

\subsection{Tribological test}

The tribological performance of lubricant was evaluated by Optimol SRV-IV oscillating reciprocating friction and wear tester. The common test condition is: Frequency $=25 \mathrm{~Hz} ;$ Load $=200 \mathrm{~N}$; Amplitude $=1 \mathrm{~mm}$; Temperature $=20{ }^{\circ} \mathrm{C}$; Time $=$ $30 \mathrm{~min}$. The changes of test conditions would be referred to the legends of figures. Three repetitive measurements were performed for each tribological process. And the standard deviation was used as the error bar in this work.

The corresponding wear volumes and morphologies of wear scars were recorded by MicroXAM-3D noncontact surface mapping profiler and JEOL JSM-5600LV scanning electron microscope (SEM) (JEOL, Japan), respectively. Then the lubricating mechanism was speculated according to the results of Raman and X-ray photoelectron spectroscope (XPS) of worn scars on the steel disks

The morphology and structure of the worn debris were analysed by FEI Tecnai F300 high-resolution transmission electron microscope (HRTEM) to speculate the change of lubricant. The preparation process of the TEM sample is as follows:

The lubricant with debris was together dispersed into petroleum ether after friction test. The copper grid covered with thin carbon film was gently immersed into the dispersion liquid to promote the adhesion of the wear debris to the surface of carbon film. The grid was then lifted off and purged with petroleum ether more than ten times to remove the residual oil on the surface.

\section{Result and Discussion}

\subsection{Structure of $M O B$}


FTIR and Raman were used to demonstrate the structure of MOB in the Figure 1a and $1 \mathrm{~b}$. The peaks of $\mathrm{C}-\mathrm{H}$ stretching vibrations in alkyl group are shown at 2890 $\mathrm{cm}^{-1}$ both in IR and Raman. $\mathrm{N}-\mathrm{H}$ and $\mathrm{C}=\mathrm{O}$ stretching vibrations with the greater change of dipole moment show the quite distinct peaks at $3305 \mathrm{~cm}^{-1}$ and $1634 \mathrm{~cm}^{-1}$ respectively in FTIR. The specific analysis of every main peak is summarized in the Table 1, which demonstrates the structure of MOB. The morphology of MOB xerogel in Figure 1c shows the formation of the fibrous structure by the self-assembly. It was speculated that the PAO8 and $\mathrm{WS}_{2}$ nanosheets can be trapped in the empty space, which was similar to the results of the previous report [16].

\subsection{Morphology and structure of $W_{2}$ nanosheets}

The morphology of $\mathrm{WS}_{2}$ nanosheets is testified by FESEM in the Figure 2a (magnification is $20000 \times$ ) and $2 \mathrm{~b}$ (magnification is $60000 \times$ ). It shows the nanosheets with the thickness of nearly $10 \mathrm{~nm}$ agglomerate haphazardly, indicating the characteristic of nanosheets. The Raman spectra in Figure 2c demonstrates the presence of two strong peaks at 352 and $421 \mathrm{~cm}^{-1}$, which correspond to the in-plane phonon mode $\left(\mathrm{E}_{2 \mathrm{~g}}^{1}\right)$ and out-of-plane phonon mode $\left(\mathrm{A}_{1 \mathrm{~g}}\right)$ modes, respectively $[3,28]$. Figure $2 \mathrm{~d}$ shows the XRD spectra of $\mathrm{WS}_{2}$ nanosheets. The planes marked as (002), (100) and (110) correspond to the diffraction angles of $14.24^{\circ}, 33.23^{\circ}$ and $58.45^{\circ}$. The broad trend of some diffraction peaks indicates the small size of $\mathrm{WS}_{2}$ nanosheets.

\subsection{Stability of the gel lubricant}

The sedimentation experiments of PAO8-1\% MOB-1\% $\mathrm{WS}_{2}$ (Figure 3a) and PAO8-1\% $\mathrm{WS}_{2}$ (Figure 3b) were recorded by digital camera to demonstrate the stability and dispersity of gel lubricant. The homogemeous and stable system is presented by PAO8-1\% MOB-1\% $\mathrm{WS}_{2}$ during the whole test period. The apparent sedimentation phenomenon emerge even after half a day in the PAO8-1\% $\mathrm{WS}_{2}$ system and the $\mathrm{WS}_{2}$ is completely sedimentated and delaminated from PAO8 oil after 10 days What's more, PAO8-1\% MOB-1\% $\mathrm{WS}_{2}$ can maintain stablility for more than 40 days. It indicates that the MOB can effectively prevent or alleviate the agglomeration and sedimentation of $\mathrm{WS}_{2}$ nanosheet in oil. And it can be reasonably speculated that this method is universally applicable for many nanomaterial to solve the problem of 
dispersity and stability.

The transmittance of PAO8-1\% $\mathrm{WS}_{2}$ and PAO8-1\% MOB-1\% $\mathrm{WS}_{2}$ were investigated by UV-Visible spectroscopy in Figure 4 to further investigate the stability of the both lubricants. It shows that the transmittance values of the two lubricants are zero for homogeneous dispersion of $\mathrm{WS}_{2}$ nanosheets in PAO8 oil at the beginning of the test. However, the transmittance value of PAO8-1\% $\mathrm{WS}_{2}$ increases to about $30 \%$ after $1 \mathrm{~d}$ standing and $60 \%$ after $2 \mathrm{~d}$ standing, indicating the apparent agglomeration and sendimentation tendency of $\mathrm{WS}_{2}$ nanosheets. The transmittance value reaches to nearly $80 \%$ after 9 days while that of PAO8-1\% MOB- $1 \% \mathrm{WS}_{2}$ maintaines 0 during the whole process. The results combining that of the above sedimentation experience both indicate the excellent stability of gel lubricants.

\subsection{Thermal properties of gel lubricant}

The thermal stabilities of PAO8, MOB, PAO8-1\% MOB and PAO8-1\% MOB-1\% $\mathrm{WS}_{2}$ were investigated respectively by TGA at air atmosphere in the Figure 4. And $30 \%, 50 \%$ and $70 \%$ of mass loss of each sample are summarized in the Table 2 for the convenient comparison. It shows that the temperatures of certain mass loss of PAO8 are slightly improved after adding 1\% MOB compared to that of pure PAO8 and the temperature of $\mathrm{PAO} 81 \% \mathrm{MOB}-1 \% \mathrm{WS}_{z}$-system demonstrates more increase than that of the other two samples, which means that the addition of $\mathrm{MOB}$ and $\mathrm{WS}_{z}$ could delay the degradation and improve the thermal stability of the lubricant system [28 29].

\subsection{Tribological performances}

\subsubsection{The effect of concentration of $W_{2}$ on the tribological performances}

Figure 5 shows that the mean friction coefficient (COF), wear volume and real-time COF of PAO8-1\% MOB with the different concentration of $\mathrm{WS}_{2}$ under the common lubricating condition. It shows that the COF value of PAO8-1\% MOB-0.1\% $\mathrm{WS}_{2}$ is more than 0.22 with the relatively large fluctuation in Figure $5 \mathrm{a}$. When the content of $\mathrm{WS}_{2}$ is increased to $0.5 \%$, the mean value of COF decreases sharply compared to that of the PAO8-1\% MOB- $0.1 \% \mathrm{WS}_{2}$ and the time of stable stage of real-time COF value is extended from $6 \mathrm{~min}$ to $13 \mathrm{~min}$ in Figure $5 \mathrm{~b}$. It can be inferred that the more $\mathrm{WS}_{2}$ can extend the lubrication lifetime of lubricant. The value of mean 
$\mathrm{COF}$ deceases rapidly when the content of $\mathrm{WS}_{2}$ increases to $1 \%$, showing the low and stable real-time COF without the distinct fluctuation during the whole lubricating process. It demonstrates that $\mathrm{PAO}-1 \% \mathrm{MOB}-1 \% \mathrm{WS}_{2}$ can exert the excellent friction-reduced and anti-wear performance. The COF values of the composite lubricant stop decreasing when the concentration of $\mathrm{WS}_{2}$ increases to $2 \%$, which means the applying saturation of $\mathrm{WS}_{2}$ nanosheets into PAO8 gel.

The wear volumes of each scar were investigated by the software of MicroXAM-3D noncontact surface mapping profiler showing in Figure 5a. The wear volume of the disk lubricated by PAO8-1\% MOB- $0.5 \% \mathrm{WS}_{2}$ decreases slightly compared to that of PAO8-1\% MOB- $0.1 \% \mathrm{WS}_{2}$ although the extended stable time appears in friction curve. With the similar tendency of COF, the wear volume of the steel disk reduced with the largest margin (decreased by 95.67\%) when the content of $\mathrm{WS}_{2}$ in $\mathrm{PAO} 8-1 \% \mathrm{MOB}$ increases to $1 \%$. The results of $\mathrm{COF}$ and wear volume indicate the dramatically friction-reducing and anti-wear performance of PAO8-1\% MOB-1\% $\mathrm{WS}_{2}$.

\subsubsection{Synergistic effect of $M O B$ and $W_{2}$ nanosheets}

The synergistic effects of $\mathrm{MOB}$ and $\mathrm{WS}_{2}$ nanosheets on the lubricating performance in steel-steel contact were investigated by the tribological tests of PAO8, PAO8-1\% MOB, PAO8-1\% $\mathrm{WS}_{2}$ and PAO8-1\% MOB-1\% $\mathrm{WS}_{2}$ with the same steel blocks and steel balls in the Figure 6. It shows that the COF value of PAO8 is more than 0.24 with the relatively large fluctuation. The mean COF value with comparative minor standard deviation decreases after adding 1\% MOB. Combining with the real-time COF in Figure 6b, it shows obviously that the COF value of pure PAO8 soar to more than 0.6 in running-in period at approximately $3 \mathrm{~min}$ and reaches the stable level at nearly 0.2 during the later lubricating stage. The stable COF value after the running-in period gradually decreases to 0.175 when lubricated by PAO8-1\% MOB, which might be inferred that $\mathrm{N}$ elememts in the gelator molecules act as the active element to react with the metal and form the tribochemical reaction film [14]. However, the friction curve of PAO8-1\% MOB indicates that the tendency of the COF curve with the sharp peak of running-in period does not change. PAO8-1\% $\mathrm{WS}_{2}$ 
possesses the better tribological performance than PAO8-1\% MOB. The COF value of PAO8-1\% $\mathrm{WS}_{2}$ decreases by the larger margin compared to that of blank PAO8 and the severe running-in period is avoid effectively, showing the longer stable time during nearly $20 \mathrm{~min}$. However, the friction curve gradually increases during the later stage of friction process, which might be caused by the agglomeration and the absented supplement of $\mathrm{WS}_{2}$ nanosheets. After adding $1 \% \mathrm{MOB}$ and $1 \% \mathrm{WS}_{2}$ nanosheets, the COF value and wear volume decrease dramatically and the friction curve keeps a low and stable value during the whole lubrication process. The tendency of wear volume is consistent with that of COF. It might be ascribed to the synergistic effect of the MOB and $\mathrm{WS}_{2}$ nanosheets. The MOB can restrict the $\mathrm{WS}_{2}$ nanosheets in its network, which could effectively prevent the agglomerate of $\mathrm{WS}_{2}$ and promote $\mathrm{WS}_{2}$ to exert the lubricating performances.

The surface morphologies of wear scars of different lubricants were recorded by SEM and 3D noncontact surface mapping profiler in Figure 7. The wear scar lubricated by pure PAO8 shows the large area damages with many deep and big pits on the worn surface, which demonstrates the tribological mechanism of that is abrasive wear. When adding 1\% MOB into PAO8, The debris exfoliated from surface is apparently smaller and less and the furrow is slighter as shown in the Figure $7 \mathrm{~b}$ and $7 b$, indicating the alleviation of abrasive wear. The obviously reduced exfoliation in Figure $7 \mathrm{c}$ and $7 \mathrm{c}^{\prime}$ demonstrates that $\mathrm{WS}_{2}$ is the better anti-wear additive than MOB for PAO8. However, the furrow is consistent with the result of the corresponding COF, indicating the failure of lubricating film and the direct contact of a certain point on the friction pair. The wear scar lubricated by PAO8-1\% MOB-1\% $\mathrm{WS}_{2}$ is nearly invisible in the Figure $7 \mathrm{~d}$ and $7 \mathrm{~d}$ ', which fully confirmed the synergistic anti-wear effect of $\mathrm{MOB}$ and $\mathrm{WS}_{2}$ nanosheets. The result is further proved by the 3D optical microscopic images shown in the Figure 7a"-d". The maximum depth of wear scar lubricated by PAO8-1\% MOB-1\% $\mathrm{WS}_{2}$ dramatically decreases than that of the other three lubricants.

\subsubsection{The effect of frequency, temperature, time and load on the tribological} performances 
To investigate the friction-reducing performance of PAO8-1\% $\mathrm{MOB}-1 \% \mathrm{WS}_{2}$ under the severe tribological condition, the effect of frequency, temperature, time and load on the COF of PAO8-1\% MOB-1\% $\mathrm{WS}_{2}$ was studied in the Figure 8. The apparent running-in period and higher $\mathrm{COF}$ value are recorded when lubricated by PAO8 oil under the four lubricating conditions. The decrease and stabilization of the COF value might be due to the re-formation of the continuous steady boundary film after the running-in period. However, $\mathrm{PAO} 8-1 \% \mathrm{MOB}-1 \% \mathrm{WS}_{2}$ presents the low and stable COF value under the wide range of frequency and temperature. The steady value of COF during the $2 \mathrm{~h}$ test shown in the Figure $8 \mathrm{c}$ demonstrates the long-term effective friction-reducing ability of PAO8-1\% MOB-1\% $\mathrm{WS}_{2}$. The load capacity of the friction pair lubricated by PAO8-1\% MOB-1\% $\mathrm{WS}_{2}$ is further improved to $500 \mathrm{~N}$. The above results fully indicate the excellent lubrication performance of PAO8-1\% MOB-1\% $\mathrm{WS}_{2}$ under the various tribological conditions.

\subsubsection{Potential applications in commercial oil}

Figure $9 \mathrm{a}$ and $9 \mathrm{~b}$ show the pictures of 5W30-1\% MOB and 5W30-1\% MOB-1\% $\mathrm{WS}_{2}$ lubricants, which indicating the excellent gelation ability of MOB in PAO8 and PAO8 with $\mathrm{WS}_{2}$ nanosheets. The tribological performances of $\mathrm{MOB}$ and $\mathrm{WS}_{2}$ nanosheets in 5W30 were investigated in Figure 9c and 9d to illustrate the potential applications of the both additives in the commercial oil. It shows that the COF and wear volume values of $5 \mathrm{~W} 30$ decrease after the addition of $1 \% \mathrm{MOB}$ and $1 \% \mathrm{WS}_{2}$. The wear volume value of $5 \mathrm{~W} 30-1 \%$ MOB-1\% $\mathrm{WS}_{2}\left(2 \times 10^{5} \mu \mathrm{m}^{3}\right)$ is lower than that of $5 \mathrm{~W} 30\left(2.5 \times 10^{5} \mu^{3}\right)$, indicating this additive can improve anti-wear property of the commercial full formula lubricant. Combined the COF curve in Figure 9b, the running-in period of $5 \mathrm{~W} 30$ are alleviated when $\mathrm{MOB}$ and $\mathrm{WS}_{2}$ added, showing the certain lubricating advantages of $5 \mathrm{~W} 30-1 \% \mathrm{MOB}-1 \% \mathrm{WS}_{2}$ than $5 \mathrm{~W} 30$ commercial oil.

\subsection{Lubricating mechanism}

The worn debris from the wear scars lubricated by PAO8-1\% $\mathrm{WS}_{2}$ (Figure 10a and 10b) and PAO8-1\% MOB-1\% $\mathrm{WS}_{2}$ (Figure 10c and 10d) under the common lubricating condition were investigated by HRTEM. As shown in Figure 10a, besides 
the obvious layer structure (part A) which might be due to the separation among interlamination during the friction process, the apparent agglomeration of $\mathrm{WS}_{2}$ is also observed. The severe agglomerations seriously influence the inherent outstanding tribological properties of $\mathrm{WS}_{2}$ during the whole friction test. $\mathrm{WS}_{2}$ in PAO8-1\% MOB do not show the obvious agglomeration like $\mathrm{WS}_{2}$ in PAO8. Figure 10c shows a large piece of $\mathrm{WS}_{2}$ with thin and translucence characteristics, indicating the separation of $\mathrm{WS}_{2}$ lamellar structure with the low shear force. The layer structure of $\mathrm{WS}_{2}$ (shown in part B) endows $\mathrm{WS}_{2}$ with the excellent lubricating property. This result also demonstrates that MOB can promote the good dispersibilty of $\mathrm{WS}_{2}$ in PAO8. The EDX spectra in Figure 10b and 10d shows a little content of $\mathrm{Fe}$ and $\mathrm{O}$, which could be the existance of $\mathrm{Fe}$ and/or iron oxide formed from the tribochemical reaction during the friction test. The iron oxide might absorb to the layer structure of $\mathrm{WS}_{2}$ during friction process to avoid the abrasion of direct contact between the steel and ball and improve the lubricating and anti-wear performance [29].

XPS is an effective tool to investigate the chemical states of elements during the friction process. The spectra of $\mathrm{S} 2 \mathrm{p}, \mathrm{N} 1 \mathrm{~s}, \mathrm{O} 1 \mathrm{~s}$ and $\mathrm{C} 1 \mathrm{~s}$ about $\mathrm{MOB}, \mathrm{WS}_{2}$ and wear scars lubricated by different lubricants were recorded by XPS (Figure 11). It shows that the S2p peak of wear scars lubricated by PAO8-1\% $\mathrm{WS}_{2}$ and PAO8-1\% MOB-1\% $\mathrm{WS}_{2}$ is different from that of $\mathrm{WS}_{2}$, which means that $\mathrm{S}$ element of $\mathrm{WS}_{2}$ takes tribochemical reaction during the lubricating process and $\mathrm{WS}_{2}$ absorbed on the surface of wear scar might be removed during the ultrasonic process before the XPS test. Combined the $\mathrm{O} 1 \mathrm{~s}$ peak at $531.6 \mathrm{eV}, \mathrm{C} 1 \mathrm{~s}$ peak at $285.6 \mathrm{eV}$ and the new peak at $168.7 \mathrm{eV}$ and $170.8 \mathrm{eV}$ of S2p, the sulphur oxides or organic sulfides are deduced to be produced when lubricated by PAO8-1\% MOB-1\% WS 2 [30-37]. The N1s peak of $\mathrm{MOB}$ at $399.4 \mathrm{eV}$ and $397.9 \mathrm{eV}$ might be assigned to $\mathrm{N}-\mathrm{H}$ [38-39] and N-C [40] respectively. The new peak at $397.3 \mathrm{eV}$ and $400.5 \mathrm{eV}$ of the wear scars lubricated by PAO8-1\% MOB and PAO8-1\% MOB-1\% $\mathrm{WS}_{2}$ could be attributed to nitrogen oxide or nitrates [41]. It also shows that the tribochemical reactions presented on the wear scar lubricated by the PAO8-1\% MOB-1\% $\mathrm{WS}_{2}$ are combined that of PAO8-1\% MOB and PAO8-1\% $\mathrm{WS}_{2}$. The O1s spectrum of wear scar lubricated by pure PAO8 at 530.0 
and $532.0 \mathrm{eV}$ can be referred to iron oxides $\left(\mathrm{Fe}_{2} \mathrm{O}_{3}\right.$ and $\left.\mathrm{Fe}_{3} \mathrm{O}_{4}\right)$ [41]. The new peaks of wear scar lubricated by PAO8-1\% MOB-1\% $\mathrm{WS}_{2}$ at 532.3 and $533.0 \mathrm{eV}$ possibly correspondence with $\mathrm{O}-\mathrm{H}$ and $\mathrm{C}-\mathrm{O}$ respectively. The comparison of $\mathrm{C} 1 \mathrm{~s}$ spectra of wear scars lubricated by PAO8 and PAO8-1\% MOB-1\% $\mathrm{WS}_{2}$ shows that the O-C-O, $\mathrm{O}=\mathrm{C}-\mathrm{O}$ and organic sulfide might produce after the addition of additive MOB and $\mathrm{WS}_{2}[36,39,42-43]$. It shows that the protective film formed by the tribochemical reaction can prevent the direct contact of the friction pair and play an important role in reducing friction and wear resistance.

The lubricating mechanism of the frequency ramp test was investigated by Raman spectra in the Figure 12 and the identification of peaks was concluded in Table 2. Figure 12 and Table 2 shows that the iron oxides, such as $\alpha-\mathrm{Fe}_{2} \mathrm{O}_{3}, \gamma-\mathrm{FeOOH}$, $\alpha-\mathrm{FeOOH}$ and $\mathrm{Fe}_{3} \mathrm{O}_{4}$, are the main reaction product on wear scar lubricated by neat PAO8. Carbonization of PAO8 might occur for the presence of the peak at $1340 \mathrm{~cm}^{-1}$ and $1570 \mathrm{~cm}^{-1}$. However, some different product might exist on the surface of wear scar lubricated by the PAO8-1\% MOB-1\% $\mathrm{WS}_{2}$. Besides the existence of $\mathrm{WS}_{2}$, iron oxide and carbonization of PAO8, some nitride and sulfide concluded in the Table 2 might be the new products of tribochemical reactions, which are conducive to the lubrication performance. It should be mentioned that the content of carbonization on the scar of the disk lubricated by PAO8-1\% MOB-1\% $\mathrm{WS}_{2}$ reduces in the Raman spectra compared with that of the disk lubricated by PAO8, which is consistent with the previous results [44-45]. Therefore, the addition of $\mathrm{MOB}$ and $\mathrm{WS}_{2}$ in PAO8 can decrease the carbonization as well as lower the COF value for the formation of physical absorbing film and tribochemical lubrication film.

The schematic diagram of the lubricating mechanisms of PAO8-1\% MOB-1\% $\mathrm{WS}_{2}$ is shown in the Figure 13. There are several factors to improve the lubrication performance of PAO8 with the additive $\mathrm{MOB}$ and $\mathrm{WS}_{2}$ nanosheets. The existence of $\mathrm{MOB}$ is conducive to the dispersibility of $\mathrm{WS}_{2}$, preventing the inhomogeneity of the additive because of the agglomeration of $\mathrm{WS}_{2}$. Meanwhile, MOB with the active element $\mathrm{N}$ in ureido has a certain friction-reducing and anti-wear properties because of the reaction with the friction pair and formation of nitride during the lubrication 
process. The $\mathrm{WS}_{2}$ nanosheet could exert the lubricating function layer by layer with the low shear force among the interlamination, which is also beneficial to the formation of the physical absorbing film on the surface of friction pairs. $\mathrm{WS}_{2}$ nanosheets which are immobilization in the network of MOB are gradually released on the friction surface, so PAO8-MOB-WS 2 presents the better long-term lubricating performance than PAO8-MOB and PAO8- $\mathrm{WS}_{2}$. And the big pieces of $\mathrm{WS}_{2}$ could adsorb or wrap up the small wear particles exfoliated from the steel surface to decrease the abrasive wear of the friction pair. The boundary films, containing the physical absorbing film and tribochemical lubrication film are formed on the surface of the friction pair, which improves the friction-reducing and anti-wear properties of PAO8. Namely, MOB and $\mathrm{WS}_{2}$ nanosheet have the synergistic effect on enhancing the tribological performance of PAO8.

\section{Conclusion}

A facile and novel method to resolve the agglomeration problem of nanomaterial in the base oil is proposed in the present work by utilizing the quick gelling ability of MOB gelator. The addition of $\mathrm{MOB}$ and $\mathrm{WS}_{z}$-nanosheet can slightly improve the thermal stability of PAO8. The tribological tests show that PAO8-1\% MOB-1\% $\mathrm{WS}_{2}$ has better lubricating and anti-wear performances than that of PAO8-1\% MOB and PAO8-1\% $\mathrm{WS}_{2}$ lubricants, which demonstrates the synergistic lubrication effects between $1 \% \mathrm{MOB}$ and $1 \% \mathrm{WS}_{2}$ nanosheets as the additives in PAO8. The immobilization function of MOB can effectively avoid the agglomeration of $\mathrm{WS}_{2}$ and promote $\mathrm{WS}_{2}$ nanosheets to exert the lubricating performance layer by layer. What's more, the tribochemical reaction which occur in $\mathrm{WS}_{2}, \mathrm{MOB}$ and the metal surface and the physical absorbing films recorded on the wear scars of steel disks can produce the strong protective film to prevent the direct contact of friction pair. The network structure of MOB gelator and the formation of boundary lubrication film play the important effects on the excellent tribological performance of PAO8 with the addition of $\mathrm{WS}_{2}$ and MOB.

\section{Acknowledgments}




\section{References}

1. Gong KL, Wu XH, Zhao GQ, Wang XB. Nanosized $\mathrm{MoS}_{2}$ deposited on graphene as lubricant additive in polyalkylene glycol for steel/steel contact at elevated temperature. Tribol Int 2017;110:1-7.

2. Rapoport L, Fleischer N, Tenne R. Fullerene - like $\mathrm{WS}_{2}$ nanoparticles: Superior lubricants for harsh conditions. Adv Mater 2003;15:651-5.

3. Joly-Pottuz L, Dassenoy F, Belin M, Vacher B, Martin JM, Fleischer N. Ultralow-friction and wear properties of IF-WS 2 under boundary lubrication. Tribol Lett 2005;18:477-85.

4. Rapoport L, Leshchinsky V, Lapsker I, Volovik Yu, Nepomnyashchy O, Lvovsky M, Popovitz-Biro R, Feldman Y and Tenne R. Tribological properties of WS2 nanoparticles under mixed lubrication. Wear 2003;255:785-93.

5. Tolman RC. The effect of droplet size on surface tension. J Chem Phys 1949;17:333-7.

6. Nanda KK, Maisels A, Kruis FE, Fissan H, Stappert S. Higher surface energy of free nanoparticles. Phys Rev Lett 2003;91:106102.

7. Rapoport L, Leshchinsky V, Lapsker I, Volovik Y, Nepomnyashchy O, Lvovsky M, Popovitz-Biro R, Feldman Y, Tenne R. Tribological properties of $\mathrm{WS}_{2}$ nanoparticles under mixed lubrication. Wear 2003;255:785-93.

8. Wu H, Zhao JW, Xia WZ, Cheng XW, He A, Yun JH, Wang LZ, Huang H, Jiao SH, Huang L, Zhang SQ, Jiang ZY. A study of the tribological behaviour of $\mathrm{TiO}_{2}$ nano-additive water-based lubricants. Tribol Int 2017;109:398-408.

9. Bao YY, Sun JL, Kong LH. Effects of nano- $\mathrm{SiO}_{2}$ as water-based lubricant additive on surface qualities of strips after hot rolling. Tribol Int 2017;114:257-63.

10. Moshkovith A, Perfiliev V, Lapsker I, Fleischer N, Tenne R, Rapoport L. Friction of fullerene-like $\mathrm{WS}_{2}$ nanoparticles: effect of agglomeration. Tribol Lett 2006;24:225-8.

11. Jiang ZQ, Zhang YJ, Yang GB, Yang KP, Zhang SM, Yu LG, Zhang PY. Tribological Properties of Oleylamine-Modified Ultrathin $\mathrm{WS}_{2}$ Nanosheets as the Additive in Polyalpha Olefin Over a Wide Temperature Range. Tribol Lett 2016;61:1-14.

12. Yu QL, Huang GW, Cai MR, Zhou F, Liu WM. In situ zwitterionic supramolecular gel lubricants for significantly improved tribological properties. Tribol Int 2016;95:55-65.

13. Foster JA, Damodaran KK, Maurin A, Day GM, Thompson HPG, Cameron GJ, Bernal JC, Steed JW. Pharmaceutical polymorph control in a drug-mimetic supramolecular gel. Chem Sci 2017;8:78-84.

14. Wu YL, He ZY, Zeng XQ, Ren TH, Vries ED, Heide EVD. Tribological and anticorrosion behaviour of novel xanthate-containing triazine derivatives in water-glycol. Tribol Int 2017;110:113-24.

15. Mandai H, Tominaga A, Yoshimura Y, Isa H. Process for producing olefin oligomer. U.S. Patent 4219691;1980.

16. Xiong Y, Liu QY, Wang H, Yang YJ. Self-assembly of a dialkylurea gelator in organic solvents in the presence of centrifugal and shearing forces. $J$ Colloid Interf Sci 
2008;318:496-500.

17. Badawi HM. Structural stability, $\mathrm{C}-\mathrm{N}$ internal rotations and vibrational spectral analysis of non-planar phenylurea and phenylthiourea. Spectrochim Acta A 2009;72:523-7.

18. Lin-Vien D, Colthup N B, Fateley W G, et al. The handbook of infrared and Raman characteristic frequencies of organic molecules. Elsevier, 1991..

19. Honziček J, Cisařova I, Vinklarek J. Acetonitrilechlorotris ( $\eta^{5}$-cyclopentadienyl) vanadium (IV) tetrachloroferrate (III). Acta Crystallogr E 2005;61:149-51.

20. Tu ZF, He Q, Chang XJ, Hu Z, Gao R, Zhang LN, Li ZH. 1-(2-Formamidoethyl)-3-phenylurea functionalized activated carbon for selective solid-phase extraction and preconcentration of metal ions. Anal Chim Acta 2009;649:252-7.

21. Frank CJ, Redd DCB, Gansler TS, McCreery RL. Characterization of human breast biopsy specimens with near-IR Raman spectroscopy. Anal Chem 1994;66:319-26.

22. Chettur G, Snelson A. Alkylperoxy and alkyl radicals. 4. Matrix IR spectra and UV photolysis of ethylperoxy and ethyl radicals. J Phys Chem 1987;91:3483-8.

23. Noda I. Two-dimensional infrared spectroscopy. J Am Chem Soc 1989;111:8116-8.

24. Koffas TS, Kim J, Lawrence CC, Somorjai GA. Detection of Immobilized Protein on Latex Microspheres by IR-Visible Sum Frequency Generation and Scanning Force Microscopy. Langmuir;2003,19:3563-6.

25. Wang T, Turhan M, Gunasekaran S. Selected properties of PH-sensitive, biodegradable chitosan-poly (vinyl alcohol) hydrogel. Polym Int 2004;53:911-8.

26. Lavalley JC, Sheppard N. Anharmonicity of $\mathrm{CH}_{3}$ deformation vibrations and Fermi resonance between the symmetrical $\mathrm{CH}_{3}$ stretching mode and overtones of $\mathrm{CH}_{3}$ deformation vibrations. Spectrochim Acta A 1972;28:2091-101.

27. Larsson K, Rand RP. Detection of changes in the environment of hydrocarbon chains by Raman spectroscopy and its application to lipid-protein systems. BBA-Lipid Lipid Met 1973;326:245-55.

28. Berkdemir A, Gutiérrez HR, Botello-Méndez AR, Perea-López N, Elías AL, Chia C, Wang B, Crespi VH, López-Urías F, Charlier J, Terrones H, Terronesa M. Identification of individual and few layers of WS2 using Raman Spectroscopy. Sci Rep 2013;3:1755.

29. Fan XQ, Wang LP. Graphene with outstanding anti-irradiation capacity as multialkylated cyclopentanes additive toward space application. Sci Rep 2015;5:12734.

30. Choi CL, Feng J, Li YG, Wu J, Zak A, Tenne R, Dai HJ. WS $\mathrm{W}_{2}$ nanoflakes from nanotubes for electrocatalysis. Nano Res 2013;6:921-8.

31. Cheng L, Huang WJ, Gong QF, Liu CH, Liu Z, Li YG, Dai HJ. Ultrathin $\mathrm{WS}_{2}$ nanoflakes as a high-performance electrocatalyst for the hydrogen evolution reaction. Angew Chem Int Edit 2014;53:7860-3.

32. Dozzi MV, Livraghi S, Giamello E, Selli E. Photocatalytic activity of S-and F-doped $\mathrm{TiO}_{2}$ in formic acid mineralization. Photochem Photobiol Sci 2011;10:343-9.

33. Cheng L, Dong SJ. A novel potentiodynamic method of electrochemical growth for layer-by-layer film formation based on electrostatic interaction. Electrochem Commun 1999; $1: 159-62$.

34. Schulze M, Lorenz M, Wagner N, Gülzow E. XPS analysis of the degradation of Nafion. Fresen J Aanal Chem 1999;365:106-13.

35. Duan JX, Yu J, Feng SL, Su L. A rapid microwave synthesis of nitrogen-sulfur co-doped 
carbon nanodots as highly sensitive and selective fluorescence probes for ascorbic acid. Talanta 2016;153:332-9.

36. Wang YR, Yu QL, Cai MR, Shi L, Zhou F and Liu WM. Synergy of lithium salt and non-ionic surfactant for significantly improved tribological properties of water-based fluids. Tribol Int 2017;113:58-64.

37. <http://srdata.nist.gov/xps/>

38. Vieira RS, Oliveira MLM, Guibal E, Rodríguez-Castellónb E, Beppu MM. Copper, mercury and chromium adsorption on natural and crosslinked chitosan films: an XPS investigation of mechanism. Colloid Surfaces A 2011;374:108-14.

39. Rajagopalan R, Iroh JO. Characterization of polyaniline-polypyrrole composite coatings on low carbon steel: a XPS and infrared spectroscopy study. Appl Surf Sci 2003;218:58-69.

40. Graat PCJ, Somers MAJ, Mittemeijer EJ. The initial oxidation of $\varepsilon-\mathrm{Fe}_{2} \mathrm{~N}_{1-\mathrm{x}}$ : an XPS investigation. Appl Surf Sci 1998;136:238-59.

41. Han YY, Qiao D, Guo YX, Feng DP, Shi L. Influence of Competitive Adsorption on Lubricating Property of Phosphonate Ionic Liquid Additives in PEG. Tribol Lett 2016;2:1-22.

42. Diaz-Terán J, Nevskaia DM, Fierro JLG, López-Peinado AJ, Jerez A. Study of chemical activation process of a lignocellulosic material with KOH by XPS and XRD. Micropor Mesopor Mat 2003;60:173-81.

43. Espinosa T, Jiménez M, Sanes J, Jiménez A, Iglesias M, Bermúdez M. Ultra-low friction with a protic ionic liquid boundary film at the water-lubricated sapphire-stainless steel interface. Tribol Lett 2014;53:1-9.

44. Lee J, Cho S, Hwang Y, Cho HJ, Lee C, Choi Y, Ku BC, Lee H, Lee B, Kim D, Kim SH. Application of fullerene-added nano-oil for lubrication enhancement in friction surfaces. Tribol Int 2009;42:440-7.

45. Lee $\mathrm{KJ}$, Wu $\mathrm{CH}$, Cheng $\mathrm{HZ}$, Kuo CC, Tseng $\mathrm{HC}$, Liao WK, Wei SF, Huang SF. Carbonization rate and impregnating methods on the tribological behavior of carbon/carbon composites. Proced Eng 2012;36:341-8.

46. Ohtsuka T, Kubo K, Sato N. Raman spectroscopy of thin corrosion films on iron at 100 to $150 \mathrm{C}$ in air. Corrosion 1986;42:476-81.

47. De Faria DLA, Venâncio Silva S, De Oliveira MT. Raman microspectroscopy of some iron oxides and oxyhydroxides. J Raman Spectrosc 1997;28:873-8.

48. Nauer G, Strecha P, Brinda-Konopik N, Liptay G. Spectroscopic and thermoanalytical characterization of standard substances for the identification of reaction products on iron electrodes. J Therm Anal Calorim 1985;30:813-30.

49. Benko B, Yu NT. Resonance Raman studies of nitric oxide binding to ferric and ferrous hemoproteins: detection of $\mathrm{Fe}$ (III)--NO stretching, Fe (III)--N--O bending, and Fe (II)--N--O bending vibrations. PNAS 1983;80:7042-6.

50. Rodríguez Pirani LS, Erben MF, Willner H, Romano RM, Della Védova CO. Matrix Isolation Study of the Conformations and Photochemistry of S-Ethyl Fluorothioformate, $\mathrm{FC}(\mathrm{O}) \mathrm{SCH}_{2} \mathrm{CH}_{3}$. J Phys Chem A 2014;118:11193-203.

51. Kumar S, Rai AK, Rai SB, Rai DK. Infrared and Raman spectra of Histidine: an ab initio DFT calculations of Histidine molecule and its different protonated forms. Indian J Phys 2010;84:563-73. 


\section{Table captions}

Table 1 Identification of the peaks of FTIR and Raman about MOB.

Table 2 Identification of the peaks of Raman spectra about wear scars lubricated by PAO8 and PAO8-1\% MOB-1\% $\mathrm{WS}_{2}$ under frequency ramp test. 


\section{Figure captions}

Fig. 1 (a) FTIR, (b) Raman spectra and (c) xerogel morphology of MOB.

Fig. 2 (a) (b) Morphologies of $\mathrm{WS}_{2}$ nanosheet with the different magnification. (c) Raman (d) XRD spectra of $\mathrm{WS}_{2}$ nanosheets.

Fig. 3 Digital picture of (a) PAO8-1\% MOB-1\% $\mathrm{WS}_{2}$ and (b) PAO8-1\% $\mathrm{WS}_{2}$ system in different time.

Fig. 4 The transmittance of (a) PAO- $1 \% \mathrm{WS}_{2}$ and (b) PAO8-1\% MOB-1\% $\mathrm{WS}_{2}$ recorded by UV-Visible spectroscopy of with the evolution of time.

Fig. 5 (a) Mean COF and wear volume (b) real-time COF of PAO8-1\% MOB-WS 2.

Fig. 6 (a) Mean COF and wear volume (b) real-time COF of PAO8, PAO8-1\% MOB, PAO8- $1 \% \mathrm{WS}_{2}$ and PAO8-1\% MOB-1\% $\mathrm{WS}_{2}$.

Fig. 7 SEM morphologies and 3D profile of worn scars on the steel disk lubricated by (a)(a')(a") PAO8, (b)(b')(b")PAO8-1\% MOB, (c)(c')(c")PAO8-1\% $\mathrm{WS}_{2}$ and (d)(d')(d")PAO8-1\% MOB-1\% $\mathrm{WS}_{2}$

Fig. 8 Evolution of COF (a) with time during a frequency ramp test from 15 to $40 \mathrm{~Hz}$ (b) with time during a temperature ramp test from 20 to $120{ }^{\circ} \mathrm{C}$ (c) of long time testing (d) with time during a load ramp test from $100 \mathrm{~N}$ to $500 \mathrm{~N}$ for pure PAO8 and PAO8-1\% MOB-1\% $\mathrm{WS}_{2}$.

Fig. 9 The picture of (a) 5W30-1\% MOB and (b) 5W30-1\% MOB-1\% $\mathrm{WS}_{2}$ lubricant; (c) Mean COF and wear volume of 5W30, 5W30-1\% MOB, 5W30-1\% $\mathrm{WS}_{2}$ and $5 \mathrm{~W} 30-1 \% \mathrm{MOB}-1 \% \mathrm{WS}_{2}(\mathrm{~d})$ real-time $\mathrm{COF}$ of $5 \mathrm{~W} 30$ and $5 \mathrm{~W} 30-1 \%$ MOB- $1 \% \mathrm{WS}_{2}$

Fig. 10 HRTEM micrographs and EDX elemental counts images of worn debris on the disk lubricated by (a) (b) PAO8-1\% $\mathrm{WS}_{2}$ and (c) (d) PAO8-1\% MOB-1\% $\mathrm{WS}_{2}$.

Fig. 11 XPS spectra of $\mathrm{S} 2 \mathrm{p}, \mathrm{N} 1 \mathrm{~s}, \mathrm{O} 1 \mathrm{~s}, \mathrm{C} 1 \mathrm{~s}$ of $\mathrm{MOB}, \mathrm{WS}_{2}$ and the worn scars lubricated by the different lubricants.

Fig. 12 Raman spectra of the wear scars lubricated by (a) PAO8 and (b) PAO8-1\% MOB-1\% $\mathrm{WS}_{2}$ under frequency ramp test.

Fig. 13 Lubricating mechenisms of PAO8-1\% MOB-1\% $\mathrm{WS}_{2}$ on the steel/steel 
friction.

2

3

4

5

9

10

11

12

13

14

15

16

17

18

19

20

21

22

23

24

25

26

27

28

29

30

31

32

33

34

35

36

37

38

39

40

41

42

43

44

45

46

47

48

49

50

51

52

53

54

55

56

57

58

59

60

61

62 
A Facile and Effective Method to Improve the Dispersibility of $\mathrm{WS}_{2}$ Nanosheets in PAO8 for the Tribological

\title{
Performances
}

\author{
Ruochong Zhang ${ }^{\mathrm{a}, \mathrm{b}}$, Dan Qiao ${ }^{\mathrm{a}}$, Xuqing Liu ${ }^{\mathrm{c}}$, Zhiguang Guo ${ }^{\mathrm{a}, \mathrm{d}}$, \\ Meirong $\mathrm{Cai}^{\mathrm{a}^{*}}$ and Lei $\mathrm{Shi}^{\mathrm{a}^{*}}$ \\ ${ }^{a}$ State Key Laboratory of Solid Lubrication, Lanzhou Institute of Chemical Physics, \\ Chinese Academy of Sciences, Lanzhou 730000, China \\ ${ }^{\mathrm{b}}$ University of Chinese Academy of Sciences, Beijing 100049, China \\ ${ }^{\mathrm{c}}$ School of Materials, University of Manchester, Oxford Road, Manchester, UK M13 \\ 9PL \\ ${ }^{\mathrm{d}}$ Hubei Collaborative Innovation Centre for Advanced Organic Chemical Materials \\ and Ministry of Education Key Laboratory for the Green Preparation and Application \\ of Functional Materials, Hubei University, Wuhan 430062, China
}

\begin{abstract}
The sedimentation of $\mathrm{WS}_{2}$ nanosheets in PAO8 is resolved by a facile method with the immobilization function of 1-methyl-2, 4-bis (N-octadecylurea) benzene (MOB), and tribological performances and mechanism of the composite lubricant are systematically investigated. Compared with blank PAO8, the composite lubricants have excellent tribological performance, which is attributed to the synergistic effect of $\mathrm{WS}_{2}$ and MOB. The immobilization function of MOB because of the network structure prevents the agglomeration and sedimentation of $\mathrm{WS}_{2}$ nanosheets. The boundary films, including tribochemical reaction film and physical absorbing film are formed on the surfaces of the friction pair during the friction process.

Keywords: dispersibility, $\mathrm{WS}_{2}$ nanosheets, tribological performance, lubricating mechanism
\end{abstract}

\footnotetext{
* Corresponding authors at: State Key Laboratory of Solid Lubrication, Lanzhou Institute of Chemical Physics, Chinese Academy of Sciences, Lanzhou 730000, PR China. E-mail addresses: leishi@licp.cas.cn (L. Shi), caimr@licp.cas.cn (M. Cai)
} 


\section{Introduction}

Some layer materials, such as graphene, $\mathrm{MoS}_{2}$ and $\mathrm{WS}_{2}$, are generally used as the additives of solid and fluid lubricants because of the lower tangential resistance deriving from the van der Waals force among interlayer [1]. And $\mathrm{WS}_{2}$ nanoparticles as the additive in oil and grease show excellent tribological performance under the severe condition. It was found that a small amount of fullerene-like $\mathrm{WS}_{2}$ nanoparticles (IF-WS ${ }_{2}$ ) added into the oil can alleviate the friction and wear remarkably as well as improve the load-bearing capacity of the friction pair [2]. Joly-Pottuz investigated the tribological performance of IF-WS 2 as additive in oil under boundary lubrication and several theories were proposed to explain the friction reducing properties. The dramatic lubrication performance of $\mathrm{WS}_{2}$ is due to the easy slide among the interlayers and the formation of the transfer film on the surface of friction pair [3]. Rapoport proposed the excellent tribological performances of IF- $\mathrm{WS}_{2}$ are attributed to the third body material transfer, which is the mixture of oil, $\mathrm{WS}_{2}$ and wear debris [4].

On the strength of thermodynamic argument, Tolman presented that the surface energy could decrease with the decrease of the particle size [5]. And the large surface energy of nanoparticle leads to the agglomeration of particle [6]. The lubricating properties of nano materials would be affected by the agglomeration tendency of nanoparticles, leading to the higher value of friction coefficient and surface worn of friction pairs [7]. At present, three major methods have been applied to improve the dispersibility of nano materials: stirring, ultrasonic treatment and chemical modification [8-9]. Moshkovith' study showed that the agglomeration of IF-WS nanoparticle had a dramatic effect on the friction and stirring was an effective method to enhance the dispersibility IF-WS 2 nanoparticles [10]. In fact, it is very difficult to use the continuous stirring and ultrasonic in the lubricating system of moving parts during the practical application. Jiang et al. studied that the ultrathin $\mathrm{WS}_{2}$ nanosheets modified by oleylamine as the additive in poly alpha olefin (PAO6), presented the good dispersion stability during 6 months and the admirable lubricating performance over the wide temperature range [11]. However, the strict reaction conditions with 
high temperature $\left(500{ }^{\circ} \mathrm{C}\right)$ and inert environment $(\mathrm{Ar})$ restrict the broad application.

According to the previous report, the low molecular weight organic gelator (LMWG) as the additive can effectively trap the base oil to improve the tribological performance and prevent the leakage of lubricant [12]. 1-methyl-2, 4-bis (N-octadecylurea) benzene (MOB) as LMWG with ureido (NH-CO-NH) shows the stronger capacity for gelating the solvent with the comparatively low content [13] and excellent tribological performance due to containing the active element $\mathrm{N}$ in ureido [14]. Utilizing the quick gelation ability of $\mathrm{MOB}$, the nano materials in base oil are trapped in the network of MOB before the agglomeration and sedimentation, obtaining the good dispersibility in base oil. However, few have been reported on the incorporation of LMWG and nanoparticles in base oil. In the present work, PAO8 oil with the addition of $\mathrm{WS}_{2}$ nanosheets was immobilized by $\mathrm{MOB}$ under a facile condition and the tribological properties and wear mechanisms of the MOB and $\mathrm{WS}_{2}$ as the additive in PAO8 were investigated.

\section{Experimental Section}

\subsection{Materials}

Toluene-2, 4-diisocyanate (TDI) was purchased from Shanghai Sanyou Chemical Reagent Co. Ltd. Octadecylamine (OA) was purchased from Tianjin Guangfu Fine Chemical Research Institute. Absolute ethanol was purchased from Rionlon Bohua (Tianjin) Pharmaceutical \& Chemical Co. Ltd. $\mathrm{WS}_{2}$ nanosheets were purchased from Huajing Powdery Material Science\&Technological Co. Ltd. PAO8 was synthesized according to the previous report [15]. All the other chemicals used in the work were of AR grade and the deionized water was used in all the experiment.

\subsection{Preparation of $M O B$}

MOB was synthesized according to previous research [16]. Briefly, $1.7 \mathrm{~g}$ (10 mmol) TDI with $100 \mathrm{~mL}$ toluene was added to toluene solvent with $5.4 \mathrm{~g} \mathrm{(20} \mathrm{mmol)}$ OA under the ice bath condition. Toluene was removed by distillation under reduced pressure after stirring the system for half an hour. The product was refluxed with absolute ethanol for half an hour to remove the remaining reactants. This procedure was repeated several times and the white product was dried $12 \mathrm{~h}$ in vacuum oven at 50 
${ }^{\circ} \mathrm{C}$ after filtrating.

\subsection{Preparation of xerogel}

The xerogel was prepared according to previous report [16]. Chlorobenzene with $3 \%$ MOB was heated and stirred to form transparent solution and then slowly cooled to the room temperature (RT). The xerogel of chlorobenzene gel was formed in freeze dryer after removing the chlorobenzene in the network of MOB.

\subsection{Preparation of lubricant}

The system of PAO8 with $\mathrm{MOB}$ or $\mathrm{WS}_{2}$ is denoted as PAO8-MOB or PAO8-WS 2 and PAO8 with both $\mathrm{MOB}$ and $\mathrm{WS}_{2}$ nanosheets is written as PAO8-MOB-WS 2 . The percentage content mentioned in this paper refers to the mass concentration.

PAO8-MOB-WS $: \mathrm{WS}_{2}$ nanosheets were dispersed in PAO8 at a given concentration by stirring for $1 \mathrm{~h}$ and ultrasonic treatment for $15 \mathrm{~min}$ in a sample vessal. A given certain content of MOB were immediately added and dissolved into PAO8 with $\mathrm{WS}_{2}$ nanosheets by heating and stirring at $140{ }^{\circ} \mathrm{C}$ for $5 \mathrm{~min}$ and then the gel lubricants were formed in several minutes when mixed solution were slowly cooled to the RT. In order to achieve the long-term stability of PAO8-MOB-WS 2 , the concentration of $\mathrm{MOB}$ was chosen as $1 \%$ although the minimum gelator content of MOB for $\mathrm{PAO} 8-\mathrm{WS}_{2}$ is $0.5 \%$

PAO8- $\mathrm{WS}_{2}: \mathrm{WS}_{2}$ nanosheets were dispersed in PAO8 at a given concentration by stirring for $1 \mathrm{~h}$ and ultrasonic treatment for $15 \mathrm{~min}$ in a sample vessal. It is used immediately after ultrasonic to keep the dispersibility and stability of $\mathrm{WS}_{2}$ nanosheets in oil.

PAO8-MOB: A given content of MOB were added into PAO8 to dissolved in base oil by heating and stirring at $140{ }^{\circ} \mathrm{C}$ for $5 \mathrm{~min}$ and then gel lubricants were formed in several minutes when mixed solution were slowly cooled to the RT.

\subsection{Characteristics}

The structure of MOB was confirmed by Nicolet iS10 FTIR spectrometer and LabRAM HR Evolution Raman. The morphology of MOB xerogel and purchased $\mathrm{WS}_{2}$ nanosheets were recorded by Field emission scanning electron microscopy 
(FESEM, JEOL JSM-6701F). The structure of $\mathrm{WS}_{2}$ was investigated by Raman and X'PERT PRO XRD. The stabilities of PAO8-1\% $\mathrm{WS}_{2}$ and PAO8-1\% MOB-1\% $\mathrm{WS}_{2}$ were studied by Agilent Technologies Cary 60 UV-Visible spectroscopy and sedimentation test.

\subsection{Tribological test}

The tribological performance of lubricant was evaluated by Optimol SRV-IV oscillating reciprocating friction and wear tester. The common test condition is: Frequency $=25 \mathrm{~Hz} ;$ Load $=200 \mathrm{~N} ;$ Amplitude $=1 \mathrm{~mm}$; Temperature $=20{ }^{\circ} \mathrm{C} ;$ Time $=$ $30 \mathrm{~min}$. The changes of test conditions would be referred to the legends of figures. Three repetitive measurements were performed for each tribological process. And the standard deviation was used as the error bar in this work.

The corresponding wear volumes and morphologies of wear scars were recorded by MicroXAM-3D noncontact surface mapping profiler and JEOL JSM-5600LV scanning electron microscope (SEM) (JEOL, Japan), respectively. Then the lubricating mechanism was speculated according to the results of Raman and X-ray photoelectron spectroscope (XPS) of worn scars on the steel disks

The morphology and structure of the worn debris were analysed by FEI Tecnai F300 high-resolution transmission electron microscope (HRTEM) to speculate the change of lubricant. The preparation process of the TEM sample is as follows:

The lubricant with debris was together dispersed into petroleum ether after friction test. The copper grid covered with thin carbon film was gently immersed into the dispersion liquid to promote the adhesion of the wear debris to the surface of carbon film. The grid was then lifted off and purged with petroleum ether more than ten times to remove the residual oil on the surface.

\section{Result and Discussion}

\subsection{Structure of $M O B$}

FTIR and Raman were used to demonstrate the structure of MOB in the Figure 1a and $1 \mathrm{~b}$. The peaks of $\mathrm{C}-\mathrm{H}$ stretching vibrations in alkyl group are shown at 2890 $\mathrm{cm}^{-1}$ both in IR and Raman. $\mathrm{N}-\mathrm{H}$ and $\mathrm{C}=\mathrm{O}$ stretching vibrations with the greater change of dipole moment show the quite distinct peaks at $3305 \mathrm{~cm}^{-1}$ and $1634 \mathrm{~cm}^{-1}$ 
respectively in FTIR. The specific analysis of every main peak is summarized in the Table 1, which demonstrates the structure of MOB. The morphology of MOB xerogel in Figure 1c shows the formation of the fibrous structure by the self-assembly. It was speculated that the PAO8 and $\mathrm{WS}_{2}$ nanosheets can be trapped in the empty space, which was similar to the results of the previous report [16].

\subsection{Morphology and structure of $W_{2}$ nanosheets}

The morphology of $\mathrm{WS}_{2}$ nanosheets is testified by FESEM in the Figure 2a (magnification is $20000 \times$ ) and $2 \mathrm{~b}$ (magnification is $60000 \times$ ). It shows the nanosheets with the thickness of nearly $10 \mathrm{~nm}$ agglomerate haphazardly, indicating the characteristic of nanosheets. The Raman spectra in Figure $2 \mathrm{c}$ demonstrates the presence of two strong peaks at 352 and $421 \mathrm{~cm}^{-1}$, which correspond to the in-plane phonon mode $\left(\mathrm{E}_{2 \mathrm{~g}}^{1}\right)$ and out-of-plane phonon mode $\left(\mathrm{A}_{1 \mathrm{~g}}\right)$ modes, respectively $[3,28]$. Figure $2 \mathrm{~d}$ shows the XRD spectra of $\mathrm{WS}_{2}$ nanosheets. The planes marked as (002), (100) and (110) correspond to the diffraction angles of $14.24^{\circ}, 33.23^{\circ}$ and $58.45^{\circ}$. The broad trend of some diffraction peaks indicates the small size of $\mathrm{WS}_{2}$ nanosheets.

\subsection{Stability of the gel lubricant}

The sedimentation experiments of PAO8-1\% MOB-1\% $\mathrm{WS}_{2}$ (Figure 3a) and PAO8-1\% $\mathrm{WS}_{2}$ (Figure 3b) were recorded by digital camera to demonstrate the stability and dispersity of gel lubricant. The homogemeous and stable system is presented by PAO8-1\% MOB-1\% $\mathrm{WS}_{2}$ during the whole test period. The apparent sedimentation phenomenon emerge even after half a day in the PAO8-1\% $\mathrm{WS}_{2}$ system and the $\mathrm{WS}_{2}$ is completely sedimentated and delaminated from PAO8 oil after 10 days. What's more, PAO8-1\% MOB-1\% $\mathrm{WS}_{2}$ can maintain stablility for more than 40 days. It indicates that the MOB can effectively prevent or alleviate the agglomeration and sedimentation of $\mathrm{WS}_{2}$ nanosheet in oil. And it can be reasonably speculated that this method is universally applicable for many nanomaterial to solve the problem of dispersity and stability.

The transmittance of PAO8-1\% $\mathrm{WS}_{2}$ and PAO8-1\% MOB-1\% $\mathrm{WS}_{2}$ were investigated by UV-Visible spectroscopy in Figure 4 to further investigate the stability of the both lubricants. It shows that the transmittance values of the two lubricants are 
zero for homogeneous dispersion of $\mathrm{WS}_{2}$ nanosheets in PAO8 oil at the beginning of the test. However, the transmittance value of PAO8-1\% $\mathrm{WS}_{2}$ increases to about $30 \%$ after $1 \mathrm{~d}$ standing and $60 \%$ after $2 \mathrm{~d}$ standing, indicating the apparent agglomeration and sendimentation tendency of $\mathrm{WS}_{2}$ nanosheets. The transmittance value reaches to nearly $80 \%$ after 9 days while that of PAO8-1\% MOB-1\% $\mathrm{WS}_{2}$ maintaines 0 during the whole process. The results combining that of the above sedimentation experience both indicate the excellent stability of gel lubricants.

\subsection{Tribological performances}

\subsubsection{The effect of concentration of $W_{2}$ on the tribological performances}

Figure 5 shows that the mean friction coefficient (COF), wear volume and real-time COF of PAO8-1\% MOB with the different concentration of $\mathrm{WS}_{2}$ under the common lubricating condition. It shows that the COF value of PAO8-1\% MOB-0.1\% $\mathrm{WS}_{2}$ is more than 0.22 with the relatively large fluctuation in Figure 5a. When the content of $\mathrm{WS}_{2}$ is increased to $0.5 \%$, the mean value of COF decreases sharply compared to that of the PAO8-1\% MOB- $-1 \% \mathrm{WS}_{2}$ and the time of stable stage of real-time COF value is extended from $6 \mathrm{~min}$ to $13 \mathrm{~min}$ in Figure $5 \mathrm{~b}$. It can be inferred that the more $\mathrm{WS}_{2}$ can extend the lubrication lifetime of lubricant. The value of mean $\mathrm{COF}$ deceases rapidly when the content of $\mathrm{WS}_{2}$ increases to $1 \%$, showing the low and stable real-time COF without the distinct fluctuation during the whole lubricating process. It demonstrates that PAO8-1\% MOB-1\% $\mathrm{WS}_{2}$ can exert the excellent friction-reduced and anti-wear performance. The $\mathrm{COF}$ values of the composite lubricant stop decreasing when the concentration of $\mathrm{WS}_{2}$ increases to $2 \%$, which means the applying saturation of $\mathrm{WS}_{2}$ nanosheets into PAO8 gel.

The wear volumes of each scar were investigated by the software of MicroXAM-3D noncontact surface mapping profiler showing in Figure 5a. The wear volume of the disk lubricated by PAO8-1\% MOB- $0.5 \% \mathrm{WS}_{2}$ decreases slightly compared to that of PAO8-1\% MOB- $0.1 \% \mathrm{WS}_{2}$ although the extended stable time appears in friction curve. With the similar tendency of COF, the wear volume of the steel disk reduced with the largest margin (decreased by 95.67\%) when the content of $\mathrm{WS}_{2}$ in $\mathrm{PAO} 8-1 \% \mathrm{MOB}$ increases to $1 \%$. The results of $\mathrm{COF}$ and wear volume 
indicate the dramatically friction-reducing and anti-wear performance of PAO8-1\% MOB- $1 \% \mathrm{WS}_{2}$.

\subsubsection{Synergistic effect of $M O B$ and $W_{2}$ nanosheets}

The synergistic effects of $\mathrm{MOB}$ and $\mathrm{WS}_{2}$ nanosheets on the lubricating performance in steel-steel contact were investigated by the tribological tests of PAO8, PAO8-1\% MOB, PAO8-1\% $\mathrm{WS}_{2}$ and PAO8-1\% MOB-1\% $\mathrm{WS}_{2}$ with the same steel blocks and steel balls in the Figure 6. It shows that the COF value of PAO8 is more than 0.24 with the relatively large fluctuation. The mean COF value with comparative minor standard deviation decreases after adding 1\% MOB. Combining with the real-time COF in Figure 6b, it shows obviously that the COF value of pure PAO8 soar to more than 0.6 in running-in period at approximately $3 \mathrm{~min}$ and reaches the stable level at nearly 0.2 during the later lubricating stage. The stable COF value after the running-in period gradually decreases to 0.175 when lubricated by PAO8-1\% MOB, which might be inferred that $\mathrm{N}$ elememts in the gelator molecules act as the active element to react with the metal and form the tribochemical reaction film [14]. However, the friction curve of PAO8-1\% MOB indicates that the tendency of the COF curve with the sharp peak of running-in period does not change. PAO8-1\% $\mathrm{WS}_{2}$ possesses the better tribological performance than PAO8-1\% MOB. The COF value of PAO8-1\% $\mathrm{WS}_{2}$ decreases by the larger margin compared to that of blank PAO8 and the severe running-in period is avoid effectively, showing the longer stable time during nearly $20 \mathrm{~min}$. However, the friction curve gradually increases during the later stage of friction process, which might be caused by the agglomeration and the absented supplement of $\mathrm{WS}_{2}$ nanosheets. After adding $1 \% \mathrm{MOB}$ and $1 \% \mathrm{WS}_{2}$ nanosheets, the COF value and wear volume decrease dramatically and the friction curve keeps a low and stable value during the whole lubrication process. The tendency of wear volume is consistent with that of COF. It might be ascribed to the synergistic effect of the MOB and $\mathrm{WS}_{2}$ nanosheets. The MOB can restrict the $\mathrm{WS}_{2}$ nanosheets in its network, which could effectively prevent the agglomerate of $\mathrm{WS}_{2}$ and promote $\mathrm{WS}_{2}$ to exert the lubricating performances.

The surface morphologies of wear scars of different lubricants were recorded by 
SEM and 3D noncontact surface mapping profiler in Figure 7. The wear scar lubricated by pure PAO8 shows the large area damages with many deep and big pits on the worn surface, which demonstrates the tribological mechanism of that is abrasive wear. When adding 1\% MOB into PAO8, The debris exfoliated from surface is apparently smaller and less and the furrow is slighter as shown in the Figure $7 \mathrm{~b}$ and $7 b$ ', indicating the alleviation of abrasive wear. The obviously reduced exfoliation in Figure $7 \mathrm{c}$ and $7 \mathrm{c}$ ' demonstrates that $\mathrm{WS}_{2}$ is the better anti-wear additive than MOB for PAO8. However, the furrow is consistent with the result of the corresponding COF, indicating the failure of lubricating film and the direct contact of a certain point on the friction pair. The wear scar lubricated by PAO8-1\% MOB-1\% $\mathrm{WS}_{2}$ is nearly invisible in the Figure $7 \mathrm{~d}$ and $7 \mathrm{~d}$ ', which fully confirmed the synergistic anti-wear effect of $\mathrm{MOB}$ and $\mathrm{WS}_{2}$ nanosheets. The result is further proved by the 3D optical microscopic images shown in the Figure 7a"-d". The maximum depth of wear scar lubricated by PAO8-1\% MOB-1\% $\mathrm{WS}_{2}$ dramatically decreases than that of the other three lubricants.

\subsubsection{The effect of frequency, temperature, time and load on the tribological performances}

To investigate the friction-reducing performance of PAO8-1\% MOB-1\% $\mathrm{WS}_{2}$ under the severe tribological condition, the effect of frequency, temperature, time and load on the COF of PAO8-1\% MOB-1\% $\mathrm{WS}_{2}$ was studied in the Figure 8. The apparent running-in period and higher COF value are recorded when lubricated by PAO8 oil under the four lubricating conditions. The decrease and stabilization of the COF value might be due to the re-formation of the continuous steady boundary film after the running-in period. However, PAO8-1\% MOB-1\% $\mathrm{WS}_{2}$ presents the low and stable COF value under the wide range of frequency and temperature. The steady value of COF during the $2 \mathrm{~h}$ test shown in the Figure $8 \mathrm{c}$ demonstrates the long-term effective friction-reducing ability of PAO8-1\% MOB-1\% $\mathrm{WS}_{2}$. The load capacity of the friction pair lubricated by PAO8-1\% MOB-1\% $\mathrm{WS}_{2}$ is further improved to $500 \mathrm{~N}$. The above results fully indicate the excellent lubrication performance of PAO8-1\% $\mathrm{MOB}-1 \% \mathrm{WS}_{2}$ under the various tribological conditions. 


\subsubsection{Potential applications in commercial oil}

Figure $9 \mathrm{a}$ and $9 \mathrm{~b}$ show the pictures of 5W30-1\% MOB and 5W30-1\% MOB-1\% $\mathrm{WS}_{2}$ lubricants, which indicating the excellent gelation ability of MOB in PAO8 and $\mathrm{PAO8}$ with $\mathrm{WS}_{2}$ nanosheets. The tribological performances of $\mathrm{MOB}$ and $\mathrm{WS}_{2}$ nanosheets in 5W30 were investigated in Figure 9c and 9d to illustrate the potential applications of the both additives in the commercial oil. It shows that the COF and wear volume values of $5 \mathrm{~W} 30$ decrease after the addition of $1 \% \mathrm{MOB}$ and $1 \% \mathrm{WS}_{2}$. The wear volume value of $5 \mathrm{~W} 30-1 \%$ MOB- $1 \% \mathrm{WS}_{2}\left(2 \times 10^{5} \mu \mathrm{m}^{3}\right)$ is lower than that of $5 \mathrm{~W} 30\left(2.5 \times 10^{5} \mu \mathrm{m}^{3}\right)$, indicating this additive can improve anti-wear property of the commercial full formula lubricant. Combined the COF curve in Figure 9b, the running-in period of $5 \mathrm{~W} 30$ are alleviated when $\mathrm{MOB}$ and $\mathrm{WS}_{2}$ added, showing the certain lubricating advantages of $5 \mathrm{~W} 30-1 \% \mathrm{MOB}-1 \% \mathrm{WS}_{2}$ than $5 \mathrm{~W} 30$ commercial oil.

\subsection{Lubricating mechanism}

The worn debris from the wear scars lubricated by PAO8-1\% $\mathrm{WS}_{2}$ (Figure 10a and 10b) and $\mathrm{PAO} 8-1 \% \mathrm{MOB}-1 \% \mathrm{WS}_{2}$ (Figure 10c and 10d) under the common lubricating condition were investigated by HRTEM. As shown in Figure 10a, besides the obvious layer structure (part A) which might be due to the separation among interlamination during the friction process, the apparent agglomeration of $\mathrm{WS}_{2}$ is also observed. The severe agglomerations seriously influence the inherent outstanding tribological properties of $\mathrm{WS}_{2}$ during the whole friction test. $\mathrm{WS}_{2}$ in PAO8-1\% MOB do not show the obvious agglomeration like $\mathrm{WS}_{2}$ in PAO8. Figure 10c shows a large piece of $\mathrm{WS}_{2}$ with thin and translucence characteristics, indicating the separation of $\mathrm{WS}_{2}$ lamellar structure with the low shear force. The layer structure of $\mathrm{WS}_{2}$ (shown in part B) endows $\mathrm{WS}_{2}$ with the excellent lubricating property. This result also demonstrates that $\mathrm{MOB}$ can promote the good dispersibilty of $\mathrm{WS}_{2}$ in PAO8. The EDX spectra in Figure 10b and 10d shows a little content of Fe and O, which could be the existance of $\mathrm{Fe}$ and/or iron oxide formed from the tribochemical reaction during the friction test. The iron oxide might absorb to the layer structure of $\mathrm{WS}_{2}$ during friction process to avoid the abrasion of direct contact between the steel and ball and 
improve the lubricating and anti-wear performance [29].

XPS is an effective tool to investigate the chemical states of elements during the friction process. The spectra of $\mathrm{S} 2 \mathrm{p}, \mathrm{N} 1 \mathrm{~s}, \mathrm{O} 1 \mathrm{~s}$ and $\mathrm{C} 1 \mathrm{~s}$ about $\mathrm{MOB}, \mathrm{WS}_{2}$ and wear scars lubricated by different lubricants were recorded by XPS (Figure 11). It shows that the S2p peak of wear scars lubricated by PAO8-1\% $\mathrm{WS}_{2}$ and PAO8-1\% MOB-1\% $\mathrm{WS}_{2}$ is different from that of $\mathrm{WS}_{2}$, which means that $\mathrm{S}$ element of $\mathrm{WS}_{2}$ takes tribochemical reaction during the lubricating process and $\mathrm{WS}_{2}$ absorbed on the surface of wear scar might be removed during the ultrasonic process before the XPS test. Combined the O1s peak at $531.6 \mathrm{eV}, \mathrm{C} 1 \mathrm{~s}$ peak at $285.6 \mathrm{eV}$ and the new peak at $168.7 \mathrm{eV}$ and $170.8 \mathrm{eV}$ of S2p, the sulphur oxides or organic sulfides are deduced to be produced when lubricated by PAO8-1\% MOB- $1 \% \mathrm{WS}_{2}$ [30-37]. The N1s peak of $\mathrm{MOB}$ at $399.4 \mathrm{eV}$ and $397.9 \mathrm{eV}$ might be assigned to $\mathrm{N}-\mathrm{H}$ [38-39] and $\mathrm{N}-\mathrm{C}$ [40] respectively. The new peak at $397.3 \mathrm{eV}$ and $400.5 \mathrm{eV}$ of the wear scars lubricated by PAO8-1\% MOB and PAO8-1\% MOB-1\% $\mathrm{WS}_{2}$ could be attributed to nitrogen oxide or nitrates [41]. It also shows that the tribochemical reactions presented on the wear scar lubricated by the PAO8-1\% MOB-1\% $\mathrm{WS}_{2}$ are combined that of PAO8-1\% MOB and PAO8-1\% $\mathrm{WS}_{2}$. The O1s spectrum of wear scar lubricated by pure PAO8 at 530.0 and $532.0 \mathrm{eV}$ can be referred to iron oxides $\left(\mathrm{Fe}_{2} \mathrm{O}_{3}\right.$ and $\left.\mathrm{Fe}_{3} \mathrm{O}_{4}\right)$ [41]. The new peaks of wear scar lubricated by PAO8-1\% MOB-1\% $\mathrm{WS}_{2}$ at 532.3 and $533.0 \mathrm{eV}$ possibly correspondence with $\mathrm{O}-\mathrm{H}$ and $\mathrm{C}-\mathrm{O}$ respectively. The comparison of $\mathrm{C} 1 \mathrm{~s}$ spectra of wear scars lubricated by PAO8 and PAO8-1\% MOB-1\% $\mathrm{WS}_{2}$ shows that the O-C-O, $\mathrm{O}=\mathrm{C}-\mathrm{O}$ and organic sulfide might produce after the addition of additive MOB and $\mathrm{WS}_{2}[36,39,42-43]$. It shows that the protective film formed by the tribochemical reaction can prevent the direct contact of the friction pair and play an important role in reducing friction and wear resistance.

The lubricating mechanism of the frequency ramp test was investigated by Raman spectra in the Figure 12 and the identification of peaks was concluded in Table 2. Figure 12 and Table 2 shows that the iron oxides, such as $\alpha-\mathrm{Fe}_{2} \mathrm{O}_{3}, \gamma-\mathrm{FeOOH}$, $\alpha-\mathrm{FeOOH}$ and $\mathrm{Fe}_{3} \mathrm{O}_{4}$, are the main reaction product on wear scar lubricated by neat PAO8. Carbonization of PAO8 might occur for the presence of the peak at $1340 \mathrm{~cm}^{-1}$ 
and $1570 \mathrm{~cm}^{-1}$. However, some different product might exist on the surface of wear scar lubricated by the PAO8-1\% MOB-1\% $\mathrm{WS}_{2}$. Besides the existence of $\mathrm{WS}_{2}$, iron oxide and carbonization of PAO8, some nitride and sulfide concluded in the Table 2 might be the new products of tribochemical reactions, which are conducive to the lubrication performance. It should be mentioned that the content of carbonization on the scar of the disk lubricated by PAO8-1\% MOB-1\% $\mathrm{WS}_{2}$ reduces in the Raman spectra compared with that of the disk lubricated by PAO8, which is consistent with the previous results [44-45]. Therefore, the addition of $\mathrm{MOB}$ and $\mathrm{WS}_{2}$ in PAO8 can decrease the carbonization as well as lower the COF value for the formation of physical absorbing film and tribochemical lubrication film.

The schematic diagram of the lubricating mechanisms of PAO8-1\% MOB-1\% $\mathrm{WS}_{2}$ is shown in the Figure 13. There are several factors to improve the lubrication performance of PAO8 with the additive $\mathrm{MOB}$ and $\mathrm{WS}_{2}$ nanosheets. The existence of $\mathrm{MOB}$ is conducive to the dispersibility of $\mathrm{WS}_{2}$, preventing the inhomogeneity of the additive because of the agglomeration of $\mathrm{WS}_{2}$. Meanwhile, MOB with the active element $\mathrm{N}$ in ureido has a certain friction-reducing and anti-wear properties because of the reaction with the friction pair and formation of nitride during the lubrication process. The $\mathrm{WS}_{2}$ nanosheet could exert the lubricating function layer by layer with the low shear force among the interlamination, which is also beneficial to the formation of the physical absorbing film on the surface of friction pairs. $\mathrm{WS}_{2}$ nanosheets which are immobilization in the network of MOB are gradually released on the friction surface, so PAO8-MOB-WS 2 presents the better long-term lubricating performance than PAO8-MOB and PAO8- $\mathrm{WS}_{2}$. And the big pieces of $\mathrm{WS}_{2}$ could adsorb or wrap up the small wear particles exfoliated from the steel surface to decrease the abrasive wear of the friction pair. The boundary films, containing the physical absorbing film and tribochemical lubrication film are formed on the surface of the friction pair, which improves the friction-reducing and anti-wear properties of PAO8. Namely, MOB and $\mathrm{WS}_{2}$ nanosheet have the synergistic effect on enhancing the tribological performance of PAO8.

\section{Conclusion}




\section{References}

1. Gong KL, Wu XH, Zhao GQ, Wang XB. Nanosized $\mathrm{MoS}_{2}$ deposited on graphene as lubricant additive in polyalkylene glycol for steel/steel contact at elevated temperature. Tribol Int 2017;110:1-7.

2. Rapoport L, Fleischer N, Tenne R. Fullerene - like $\mathrm{WS}_{2}$ nanoparticles: Superior lubricants for harsh conditions. Adv Mater 2003;15:651-5.

3. Joly-Pottuz L, Dassenoy F, Belin M, Vacher B, Martin JM, Fleischer N. Ultralow-friction and wear properties of IF-WS 2 under boundary lubrication. Tribol Lett 2005;18:477-85.

4. Rapoport L, Leshchinsky V, Lapsker I, Volovik Yu, Nepomnyashchy O, Lvovsky M, Popovitz-Biro R, Feldman Y and Tenne R. Tribological properties of WS2 nanoparticles under mixed lubrication. Wear 2003;255:785-93.

5. Tolman RC. The effect of droplet size on surface tension. J Chem Phys 1949;17:333-7.

6. Nanda KK, Maisels A, Kruis FE, Fissan H, Stappert S. Higher surface energy of free nanoparticles. Phys Rev Lett 2003;91:106102.

7. Rapoport L, Leshchinsky V, Lapsker I, Volovik Y, Nepomnyashchy O, Lvovsky M, Popovitz-Biro R, Feldman Y, Tenne R. Tribological properties of $\mathrm{WS}_{2}$ nanoparticles under mixed lubrication. Wear 2003;255:785-93. 
8. Wu H, Zhao JW, Xia WZ, Cheng XW, He A, Yun JH, Wang LZ, Huang H, Jiao SH, Huang L, Zhang SQ, Jiang ZY. A study of the tribological behaviour of $\mathrm{TiO}_{2}$ nano-additive water-based lubricants. Tribol Int 2017;109:398-408.

9. Bao YY, Sun JL, Kong LH. Effects of nano- $\mathrm{SiO}_{2}$ as water-based lubricant additive on surface qualities of strips after hot rolling. Tribol Int 2017;114:257-63.

10. Moshkovith A, Perfiliev V, Lapsker I, Fleischer N, Tenne R, Rapoport L. Friction of fullerene-like $\mathrm{WS}_{2}$ nanoparticles: effect of agglomeration. Tribol Lett 2006;24:225-8.

11. Jiang ZQ, Zhang YJ, Yang GB, Yang KP, Zhang SM, Yu LG, Zhang PY. Tribological Properties of Oleylamine-Modified Ultrathin $\mathrm{WS}_{2}$ Nanosheets as the Additive in Polyalpha Olefin Over a Wide Temperature Range. Tribol Lett 2016;61:1-14.

12. Yu QL, Huang GW, Cai MR, Zhou F, Liu WM. In situ zwitterionic supramolecular gel lubricants for significantly improved tribological properties. Tribol Int 2016;95:55-65.

13. Foster JA, Damodaran KK, Maurin A, Day GM, Thompson HPG, Cameron GJ, Bernal JC, Steed JW. Pharmaceutical polymorph control in a drug-mimetic supramolecular gel. Chem Sci 2017;8:78-84.

14. Wu YL, He ZY, Zeng XQ, Ren TH, Vries ED, Heide EVD. Tribological and anticorrosion behaviour of novel xanthate-containing triazine derivatives in water-glycol. Tribol Int 2017;110:113-24.

15. Mandai $\mathrm{H}$, Tominaga A, Yoshimura Y, Isa H. Process for producing olefin oligomer. U.S. Patent 4219691;1980.

16. Xiong Y, Liu QY, Wang H, Yang YJ. Self-assembly of a dialkylurea gelator in organic solvents in the presence of centrifugal and shearing forces. J Colloid Interf Sci 2008;318:496-500.

17. Badawi HM. Structural stability, $\mathrm{C}-\mathrm{N}$ internal rotations and vibrational spectral analysis of non-planar phenylurea and phenylthiourea. Spectrochim Acta A 2009;72:523-7.

18. Lin-Vien D, Colthup N B, Fateley W G, et al. The handbook of infrared and Raman characteristic frequencies of organic molecules. Elsevier, $1991 .$.

19. Honziček J, Cisařova I, Vinklarek J. Acetonitrilechlorotris ( $\eta^{5}$-cyclopentadienyl) vanadium (IV) tetrachloroferrate (III). Acta Crystallogr E 2005;61:149-51.

20. Tu ZF, He Q, Chang XJ, Hu Z, Gao R, Zhang LN, Li ZH. 1-(2-Formamidoethyl)-3-phenylurea functionalized activated carbon for selective solid-phase extraction and preconcentration of metal ions. Anal Chim Acta 2009;649:252-7.

21. Frank CJ, Redd DCB, Gansler TS, McCreery RL. Characterization of human breast biopsy specimens with near-IR Raman spectroscopy. Anal Chem 1994;66:319-26.

22. Chettur G, Snelson A. Alkylperoxy and alkyl radicals. 4. Matrix IR spectra and UV photolysis of ethylperoxy and ethyl radicals. J Phys Chem 1987;91:3483-8.

23. Noda I. Two-dimensional infrared spectroscopy. J Am Chem Soc 1989;111:8116-8.

24. Koffas TS, Kim J, Lawrence CC, Somorjai GA. Detection of Immobilized Protein on Latex Microspheres by IR-Visible Sum Frequency Generation and Scanning Force Microscopy. Langmuir;2003,19:3563-6.

25. Wang T, Turhan M, Gunasekaran S. Selected properties of PH-sensitive, biodegradable chitosan-poly (vinyl alcohol) hydrogel. Polym Int 2004;53:911-8.

26. Lavalley JC, Sheppard N. Anharmonicity of $\mathrm{CH}_{3}$ deformation vibrations and Fermi resonance between the symmetrical $\mathrm{CH}_{3}$ stretching mode and overtones of $\mathrm{CH}_{3}$ deformation 
vibrations. Spectrochim Acta A 1972;28:2091-101.

27. Larsson K, Rand RP. Detection of changes in the environment of hydrocarbon chains by Raman spectroscopy and its application to lipid-protein systems. BBA-Lipid Lipid Met 1973;326:245-55.

28. Berkdemir A, Gutiérrez HR, Botello-Méndez AR, Perea-López N, Elías AL, Chia C, Wang B, Crespi VH, López-Urías F, Charlier J, Terrones H, Terronesa M. Identification of individual and few layers of WS2 using Raman Spectroscopy. Sci Rep 2013;3:1755.

29. Fan XQ, Wang LP. Graphene with outstanding anti-irradiation capacity as multialkylated cyclopentanes additive toward space application. Sci Rep 2015;5:12734.

30. Choi CL, Feng J, Li YG, Wu J, Zak A, Tenne R, Dai HJ. WS ${ }_{2}$ nanoflakes from nanotubes for electrocatalysis. Nano Res 2013;6:921-8.

31. Cheng L, Huang WJ, Gong QF, Liu CH, Liu Z, Li YG, Dai HJ. Ultrathin $\mathrm{WS}_{2}$ nanoflakes as a high-performance electrocatalyst for the hydrogen evolution reaction. Angew Chem Int Edit 2014;53:7860-3.

32. Dozzi MV, Livraghi S, Giamello E, Selli E. Photocatalytic activity of S-and F-doped $\mathrm{TiO}_{2}$ in formic acid mineralization. Photochem Photobiol Sci 2011;10:343-9.

33. Cheng L, Dong SJ. A novel potentiodynamic method of electrochemical growth for layer-by-layer film formation based on electrostatic interaction. Electrochem Commun 1999;1:159-62.

34. Schulze M, Lorenz M, Wagner N, Gülzow E. XPS analysis of the degradation of Nafion. Fresen J Aanal Chem 1999;365:106-13.

35. Duan JX, Yu J, Feng SL, Su L. A rapid microwave synthesis of nitrogen-sulfur co-doped carbon nanodots as highly sensitive and selective fluorescence probes for ascorbic acid. Talanta 2016;153:332-9.

36. Wang YR, Yu QL, Cai MR, Shi L, Zhou F and Liu WM. Synergy of lithium salt and non-ionic surfactant for significantly improved tribological properties of water-based fluids. Tribol Int 2017;113:58-64.

37. <http://srdata.nist.gov/xps/>

38. Vieira RS, Oliveira MLM, Guibal E, Rodríguez-Castellónb E, Beppu MM. Copper, mercury and chromium adsorption on natural and crosslinked chitosan films: an XPS investigation of mechanism. Colloid Surfaces A 2011;374:108-14.

39. Rajagopalan R, Iroh JO. Characterization of polyaniline-polypyrrole composite coatings on low carbon steel: a XPS and infrared spectroscopy study. Appl Surf Sci 2003;218:58-69.

40. Graat PCJ, Somers MAJ, Mittemeijer EJ. The initial oxidation of $\varepsilon-\mathrm{Fe}_{2} \mathrm{~N}_{1-\mathrm{x}}$ : an XPS investigation. Appl Surf Sci 1998;136:238-59.

41. Han YY, Qiao D, Guo YX, Feng DP, Shi L. Influence of Competitive Adsorption on Lubricating Property of Phosphonate Ionic Liquid Additives in PEG. Tribol Lett 2016;2:1-22.

42. Diaz-Terán J, Nevskaia DM, Fierro JLG, López-Peinado AJ, Jerez A. Study of chemical activation process of a lignocellulosic material with KOH by XPS and XRD. Micropor Mesopor Mat 2003;60:173-81.

43. Espinosa T, Jiménez M, Sanes J, Jiménez A, Iglesias M, Bermúdez M. Ultra-low friction with a protic ionic liquid boundary film at the water-lubricated sapphire-stainless steel interface. Tribol Lett 2014;53:1-9.

44. Lee J, Cho S, Hwang Y, Cho HJ, Lee C, Choi Y, Ku BC, Lee H, Lee B, Kim D, Kim SH. 
Application of fullerene-added nano-oil for lubrication enhancement in friction surfaces. Tribol Int 2009;42:440-7.

45. Lee $\mathrm{KJ}$, Wu CH, Cheng $\mathrm{HZ}$, Kuo CC, Tseng HC, Liao WK, Wei SF, Huang SF. Carbonization rate and impregnating methods on the tribological behavior of carbon/carbon composites. Proced Eng 2012;36:341-8.

46. Ohtsuka T, Kubo K, Sato N. Raman spectroscopy of thin corrosion films on iron at 100 to $150 \mathrm{C}$ in air. Corrosion 1986;42:476-81.

47. De Faria DLA, Venâncio Silva S, De Oliveira MT. Raman microspectroscopy of some iron oxides and oxyhydroxides. J Raman Spectrosc 1997;28:873-8.

48. Nauer G, Strecha P, Brinda-Konopik N, Liptay G. Spectroscopic and thermoanalytical characterization of standard substances for the identification of reaction products on iron electrodes. J Therm Anal Calorim 1985;30:813-30.

49. Benko B, Yu NT. Resonance Raman studies of nitric oxide binding to ferric and ferrous hemoproteins: detection of Fe (III)--NO stretching, Fe (III)--N--O bending, and Fe (II)--N--O bending vibrations. PNAS 1983;80:7042-6.

50. Rodríguez Pirani LS, Erben MF, Willner H, Romano RM, Della Védova CO. Matrix Isolation Study of the Conformations and Photochemistry of S-Ethyl Fluorothioformate, FC(O)SCH${ }_{2} \mathrm{CH}_{3}$. J Phys Chem A 2014;118:11193-203.

51. Kumar S, Rai AK, Rai SB, Rai DK. Infrared and Raman spectra of Histidine: an ab initio DFT calculations of Histidine molecule and its different protonated forms. Indian $\mathrm{J}$ Phys 2010;84:563-73. 


\section{Table captions}

Table 1 Identification of the peaks of FTIR and Raman about MOB.

Table 2 Identification of the peaks of Raman spectra about wear scars lubricated by PAO8 and PAO8-1\% MOB-1\% $\mathrm{WS}_{2}$ under frequency ramp test. 


\section{Figure captions}

Fig. 1 (a) FTIR, (b) Raman spectra and (c) xerogel morphology of MOB.

Fig. 2 (a) (b) Morphologies of $\mathrm{WS}_{2}$ nanosheet with the different magnification. (c) Raman (d) XRD spectra of $\mathrm{WS}_{2}$ nanosheets.

Fig. 3 Digital picture of (a) PAO8-1\% MOB-1\% $\mathrm{WS}_{2}$ and (b) PAO8-1\% $\mathrm{WS}_{2}$ system in different time.

Fig. 4 The transmittance of (a) PAO- $1 \% \mathrm{WS}_{2}$ and (b) PAO8-1\% MOB-1\% $\mathrm{WS}_{2}$ recorded by UV-Visible spectroscopy of with the evolution of time.

Fig. 5 (a) Mean COF and wear volume (b) real-time COF of PAO8-1\% MOB-WS 2.

Fig. 6 (a) Mean COF and wear volume (b) real-time COF of PAO8, PAO8-1\% MOB, PAO8- $1 \% \mathrm{WS}_{2}$ and PAO8-1\% MOB-1\% $\mathrm{WS}_{2}$.

Fig. 7 SEM morphologies and 3D profile of worn scars on the steel disk lubricated by (a)(a')(a") PAO8, (b)(b')(b")PAO8-1\% MOB, (c)(c')(c")PAO8-1\% $\mathrm{WS}_{2}$ and (d)(d')(d")PAO8-1\% MOB-1\% $\mathrm{WS}_{2}$

Fig. 8 Evolution of COF (a) with time during a frequency ramp test from 15 to $40 \mathrm{~Hz}$ (b) with time during a temperature ramp test from 20 to $120{ }^{\circ} \mathrm{C}$ (c) of long time testing (d) with time during a load ramp test from $100 \mathrm{~N}$ to $500 \mathrm{~N}$ for pure PAO8 and PAO8-1\% MOB-1\% $\mathrm{WS}_{2}$.

Fig. 9 The picture of (a) 5W30-1\% MOB and (b) 5W30-1\% MOB-1\% $\mathrm{WS}_{2}$ lubricant; (c) Mean COF and wear volume of 5W30, 5W30-1\% MOB, 5W30-1\% $\mathrm{WS}_{2}$ and $5 \mathrm{~W} 30-1 \% \mathrm{MOB}-1 \% \mathrm{WS}_{2}(\mathrm{~d})$ real-time $\mathrm{COF}$ of $5 \mathrm{~W} 30$ and $5 \mathrm{~W} 30-1 \%$ MOB- $1 \% \mathrm{WS}_{2}$

Fig. 10 HRTEM micrographs and EDX elemental counts images of worn debris on the disk lubricated by (a) (b) PAO8-1\% $\mathrm{WS}_{2}$ and (c) (d) PAO8-1\% MOB-1\% $\mathrm{WS}_{2}$.

Fig. 11 XPS spectra of $\mathrm{S} 2 \mathrm{p}, \mathrm{N} 1 \mathrm{~s}, \mathrm{O} 1 \mathrm{~s}, \mathrm{C} 1 \mathrm{~s}$ of $\mathrm{MOB}, \mathrm{WS}_{2}$ and the worn scars lubricated by the different lubricants.

Fig. 12 Raman spectra of the wear scars lubricated by (a) PAO8 and (b) PAO8-1\% MOB-1\% $\mathrm{WS}_{2}$ under frequency ramp test.

Fig. 13 Lubricating mechenisms of PAO8-1\% MOB-1\% $\mathrm{WS}_{2}$ on the steel/steel 
friction.

2

3

4

5

9

10

11

12

13

14

15

16

17

18

19

20

21

22

23

24

25

26

27

28

29

30

31

32

33

34

35

36

37

38

39

40

41

42

43

44

45

46

47

48

49

50

51

52

53

54

55

56

57

58

59

60

61

62 

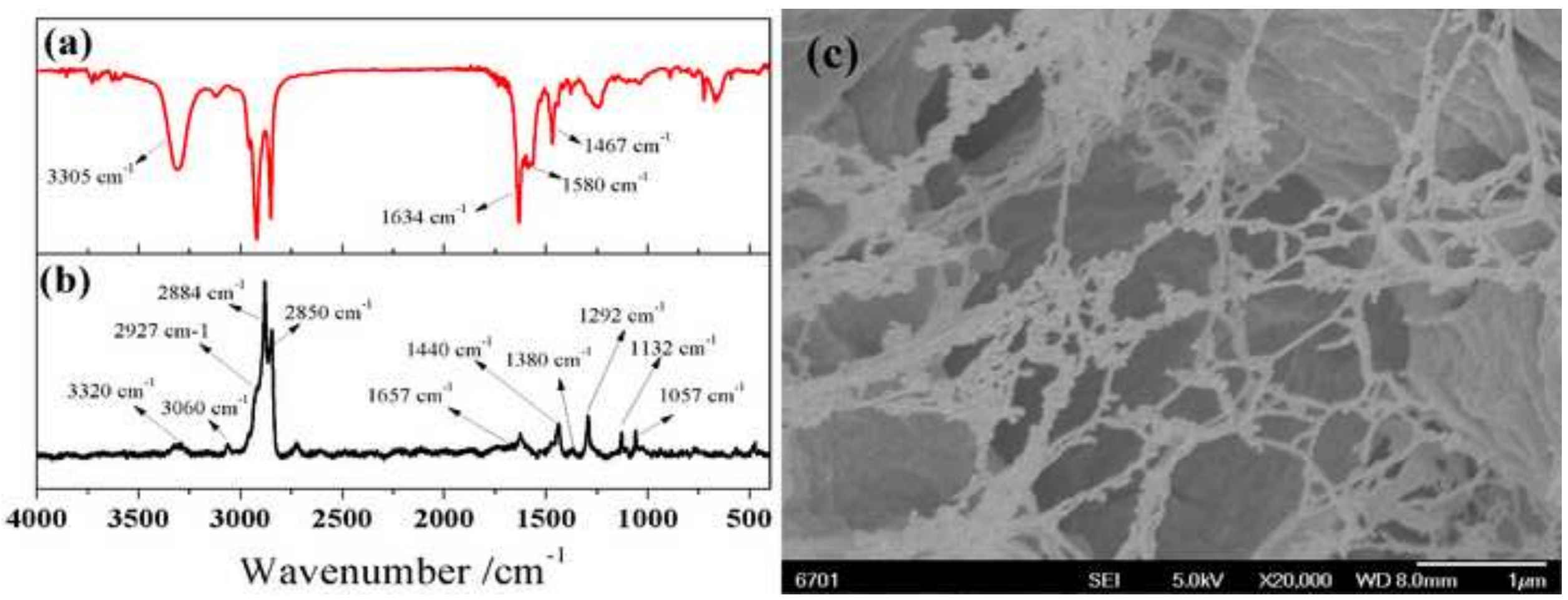

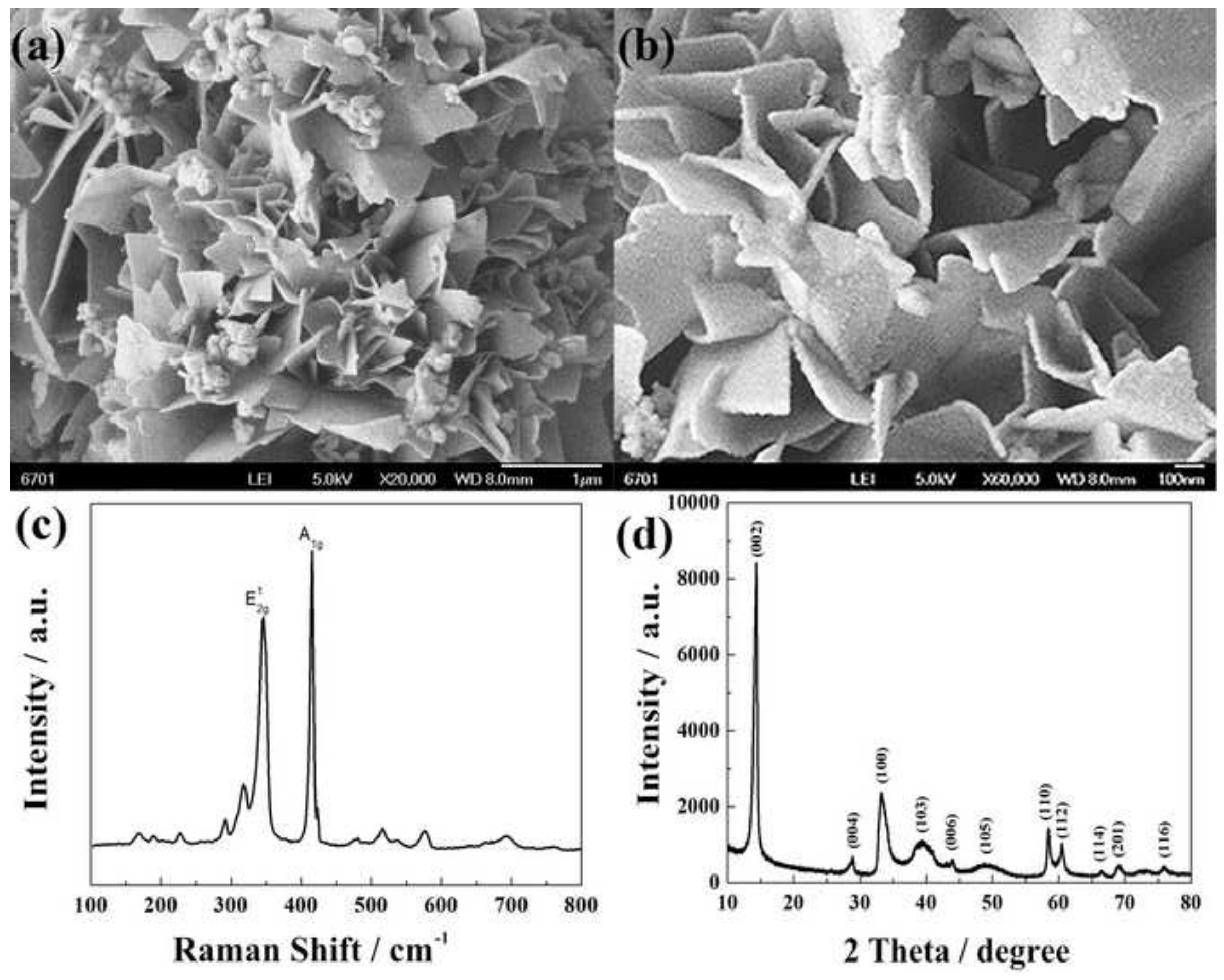
(a)
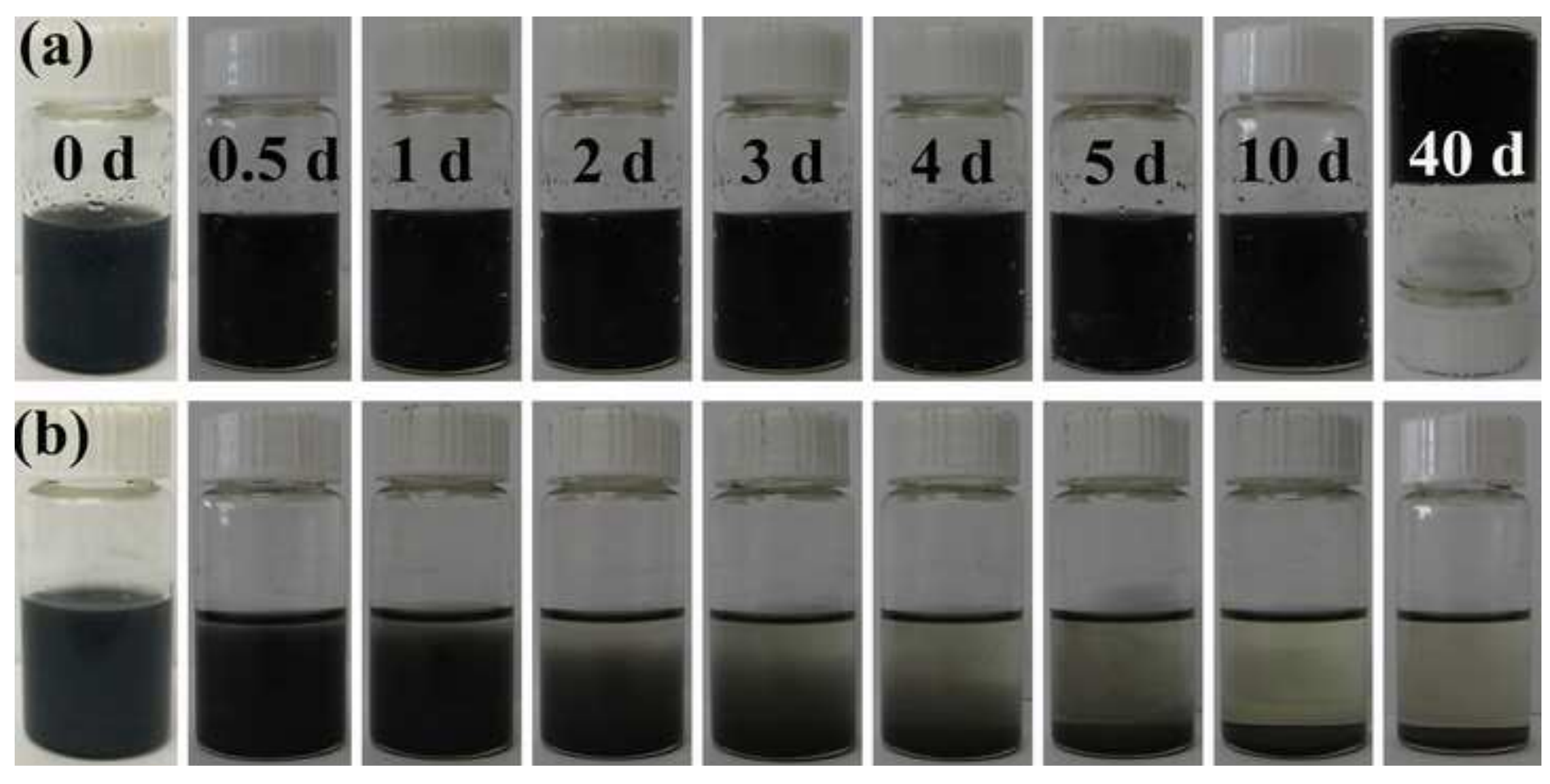

$40 \mathrm{~d}$ 

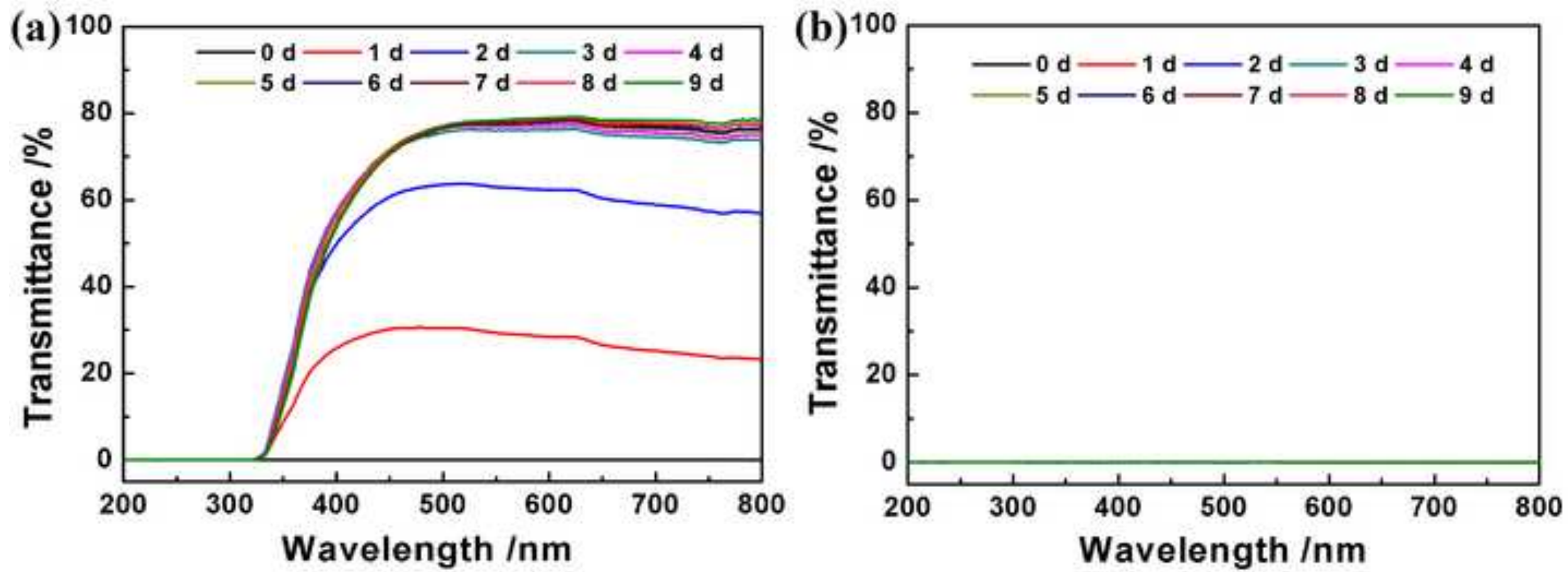

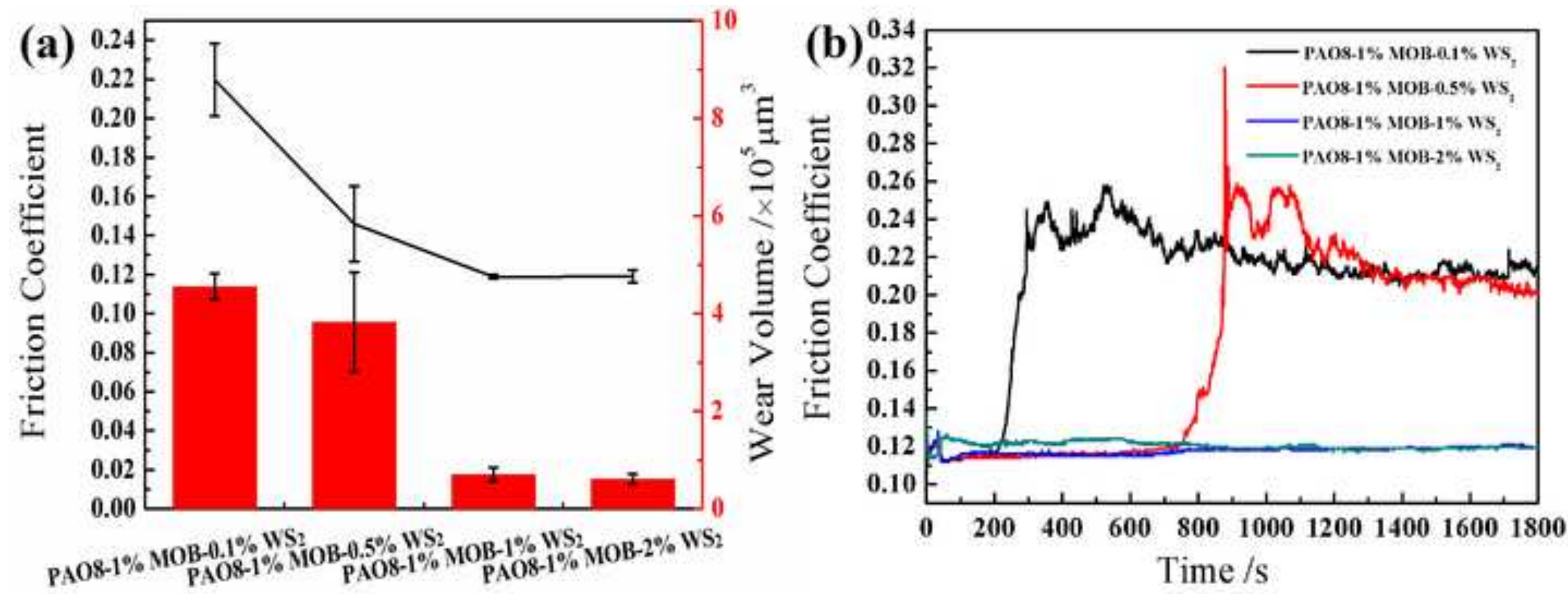

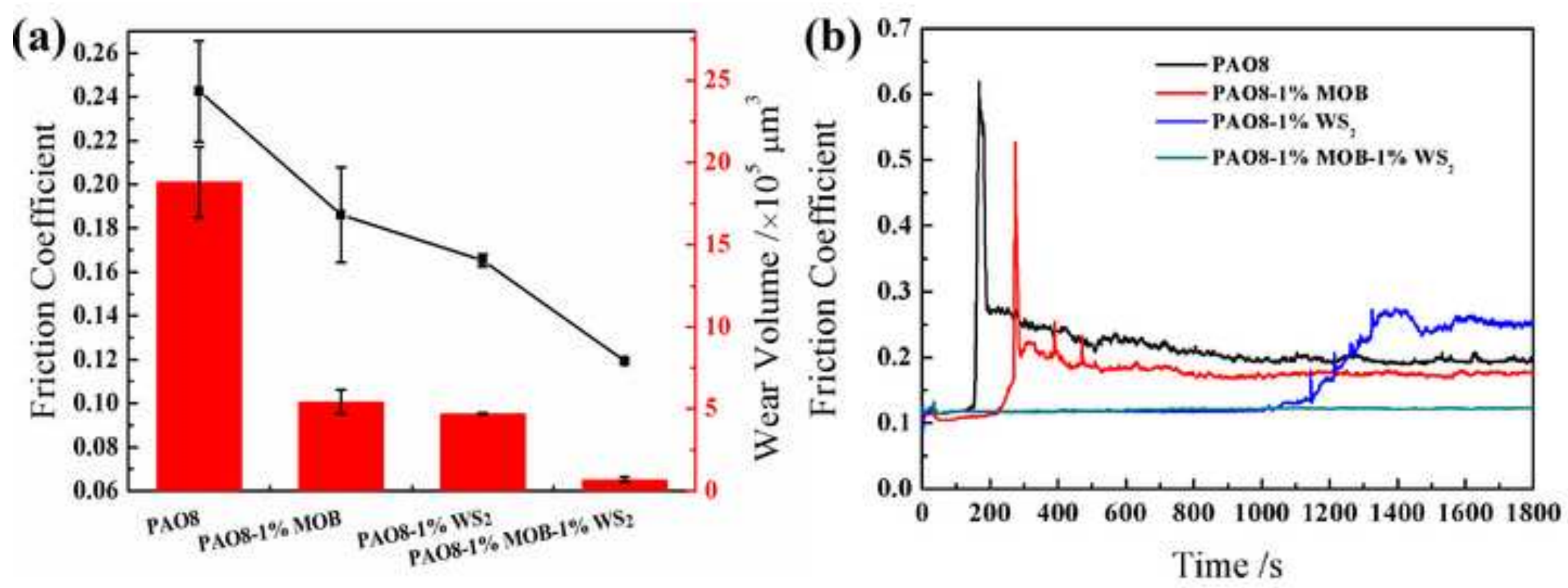

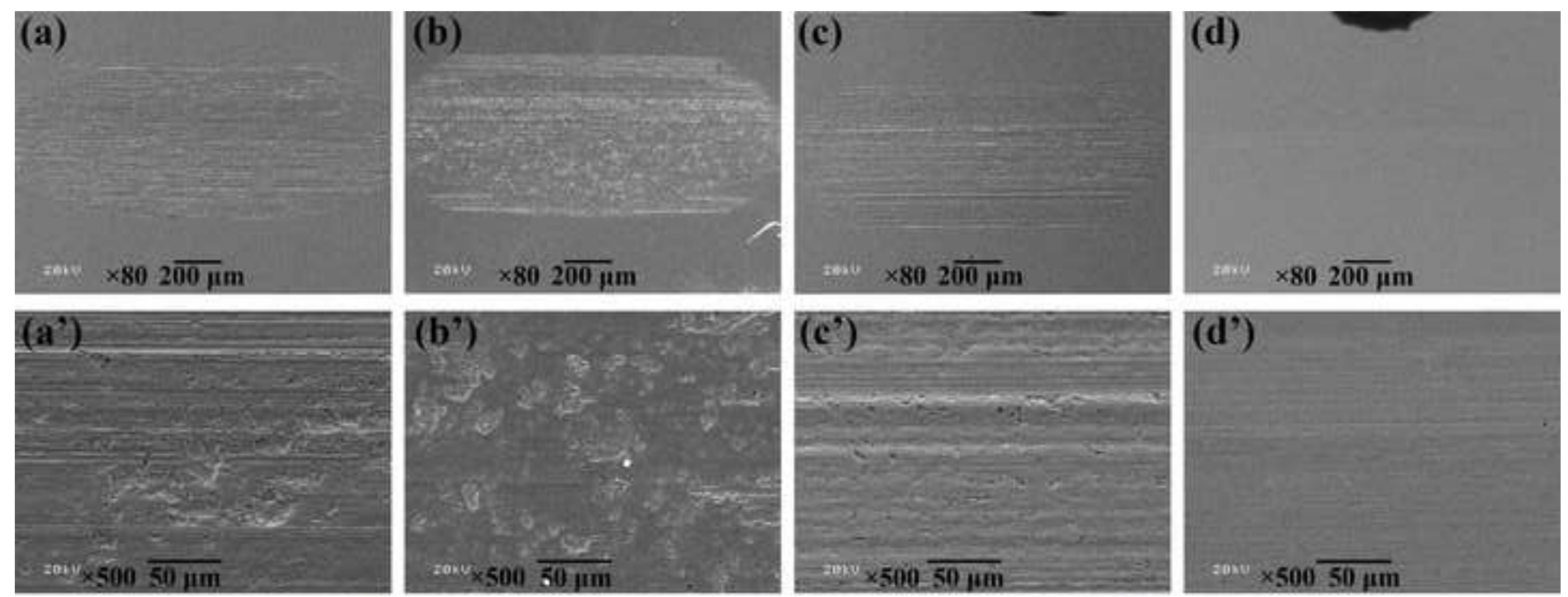

\section{(d')}

2008 $\times 500 \overline{50 \mu \mathrm{m}}$
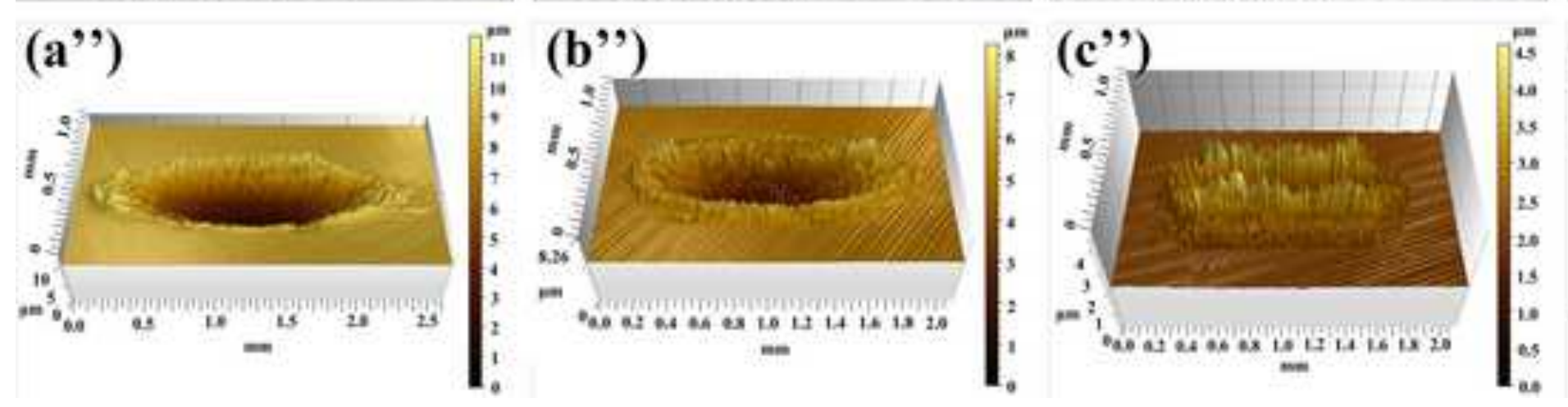

soxu $\times 500 \overline{50 \mu \mathrm{m}}$

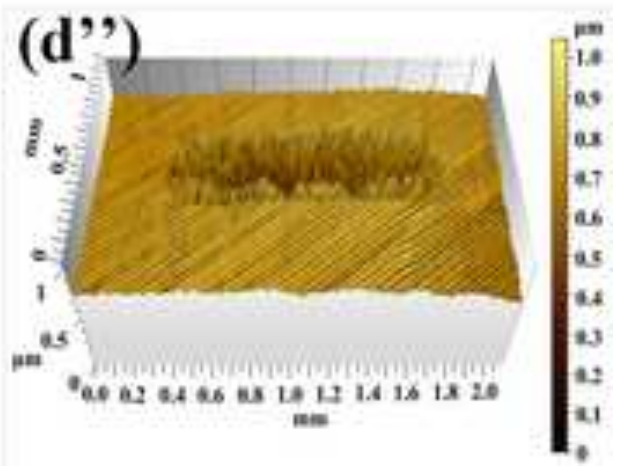



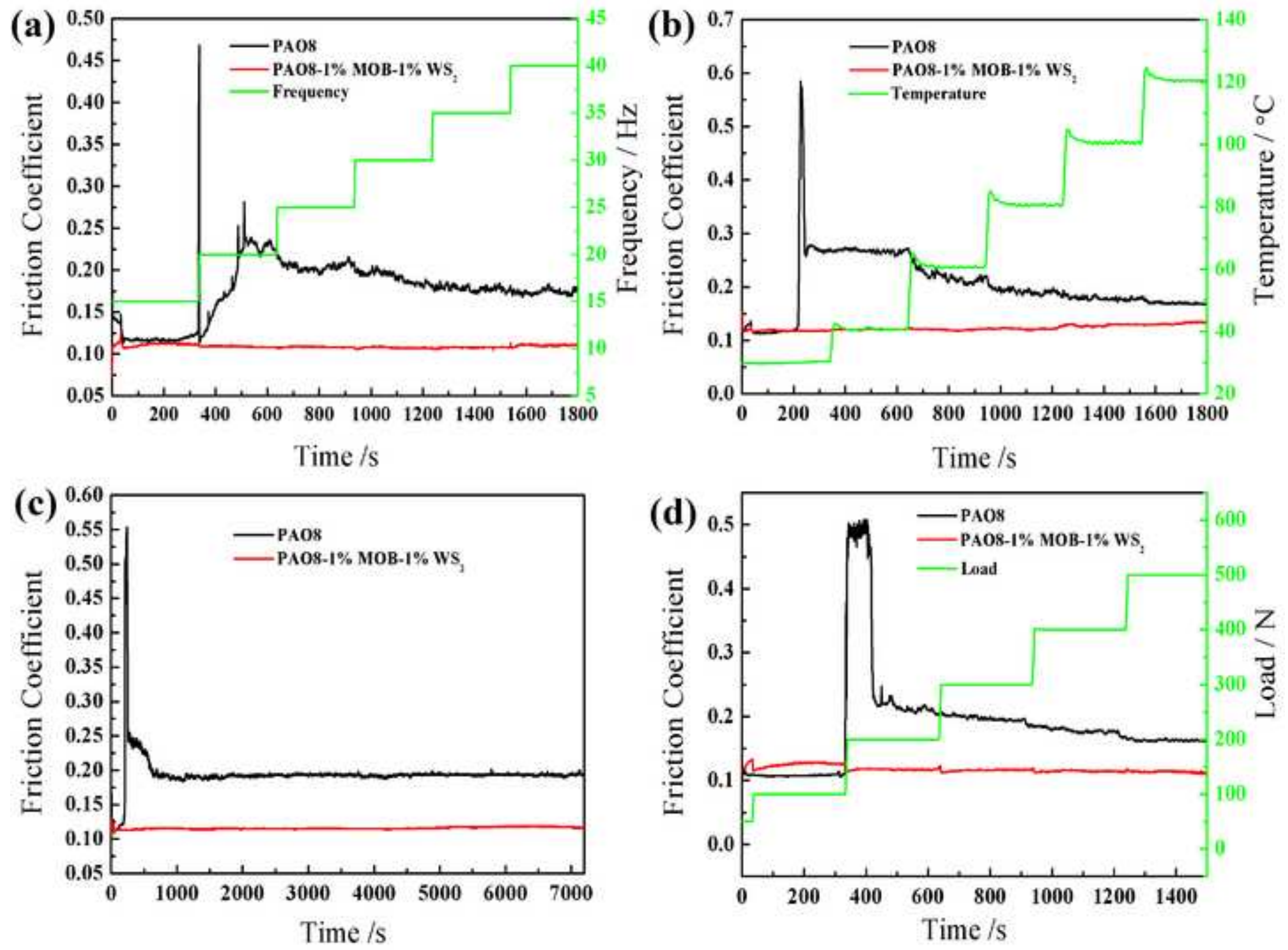

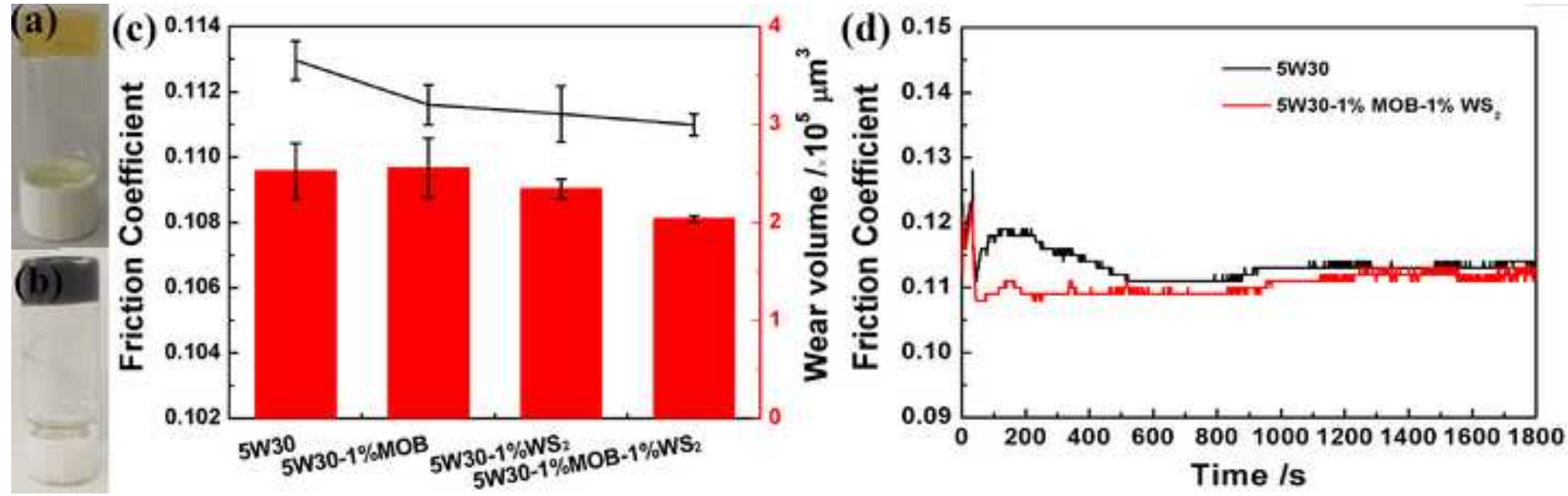

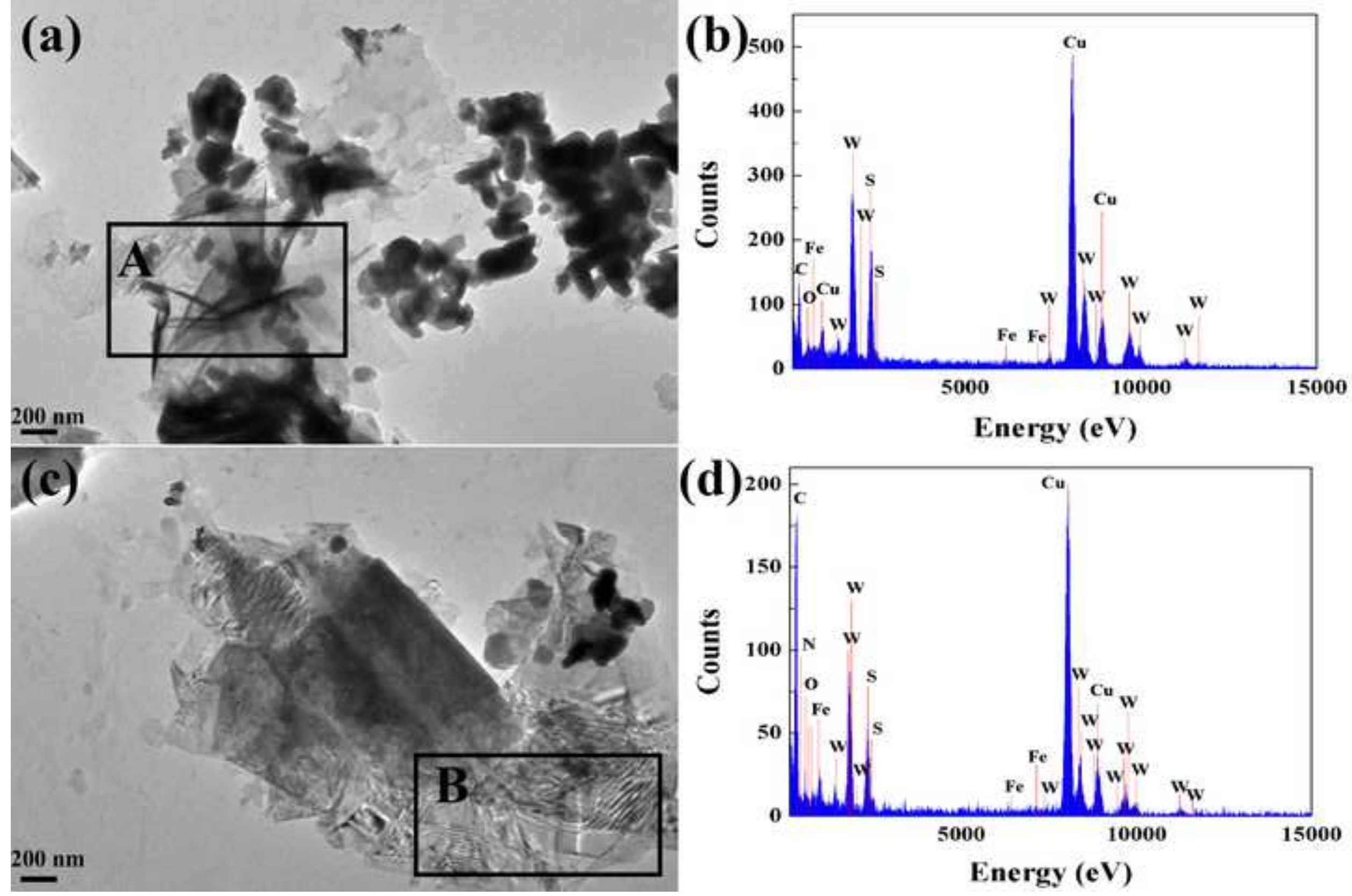


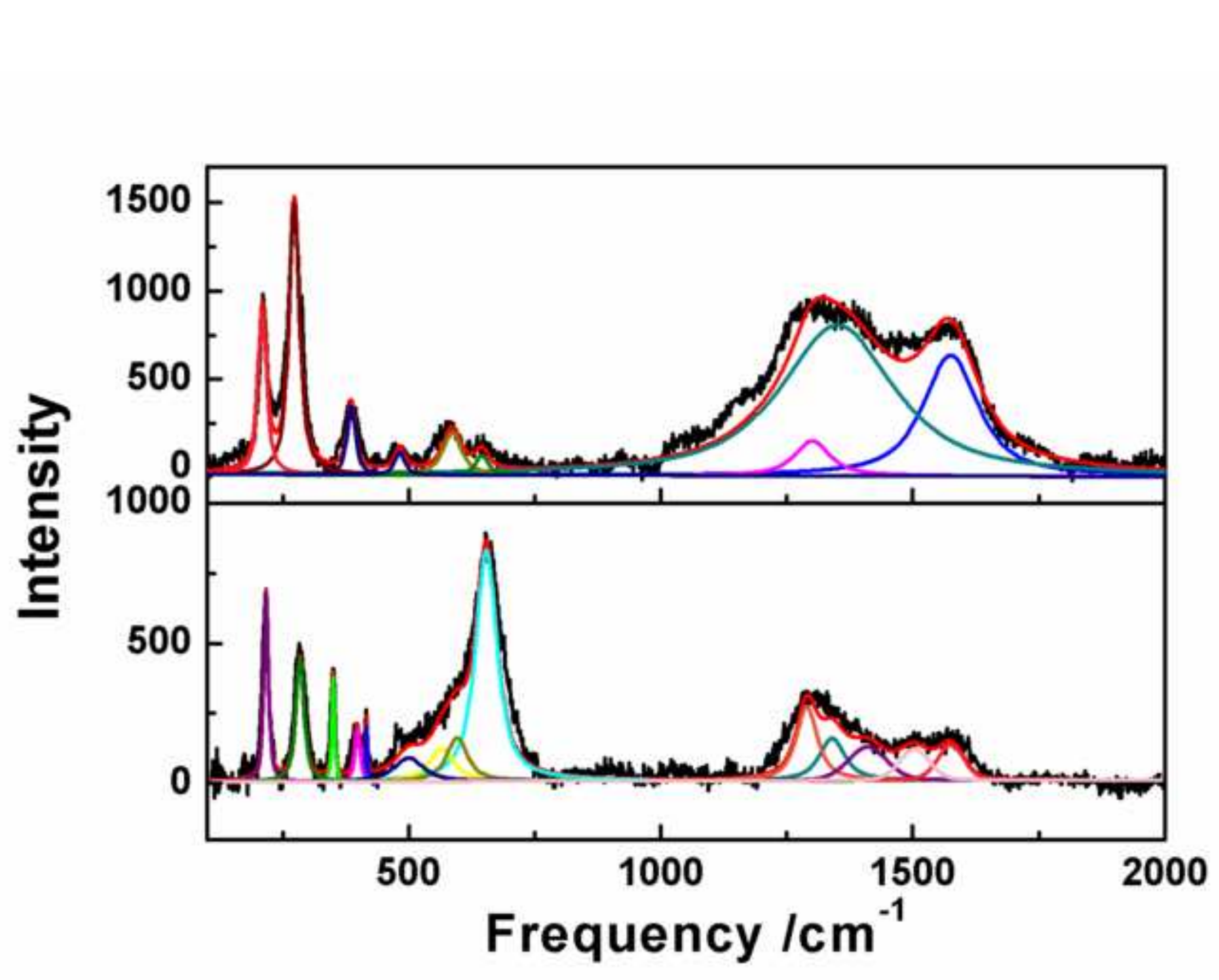

.


(a)

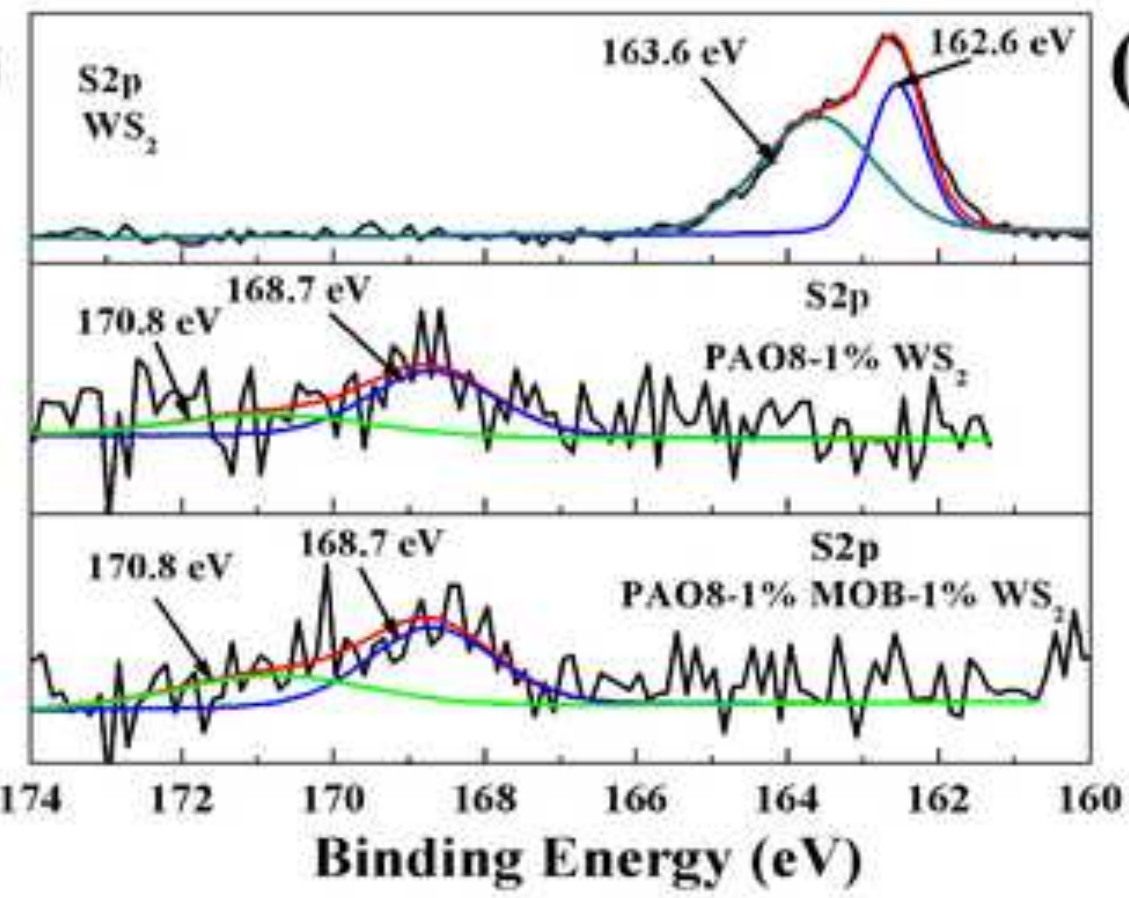

(c)

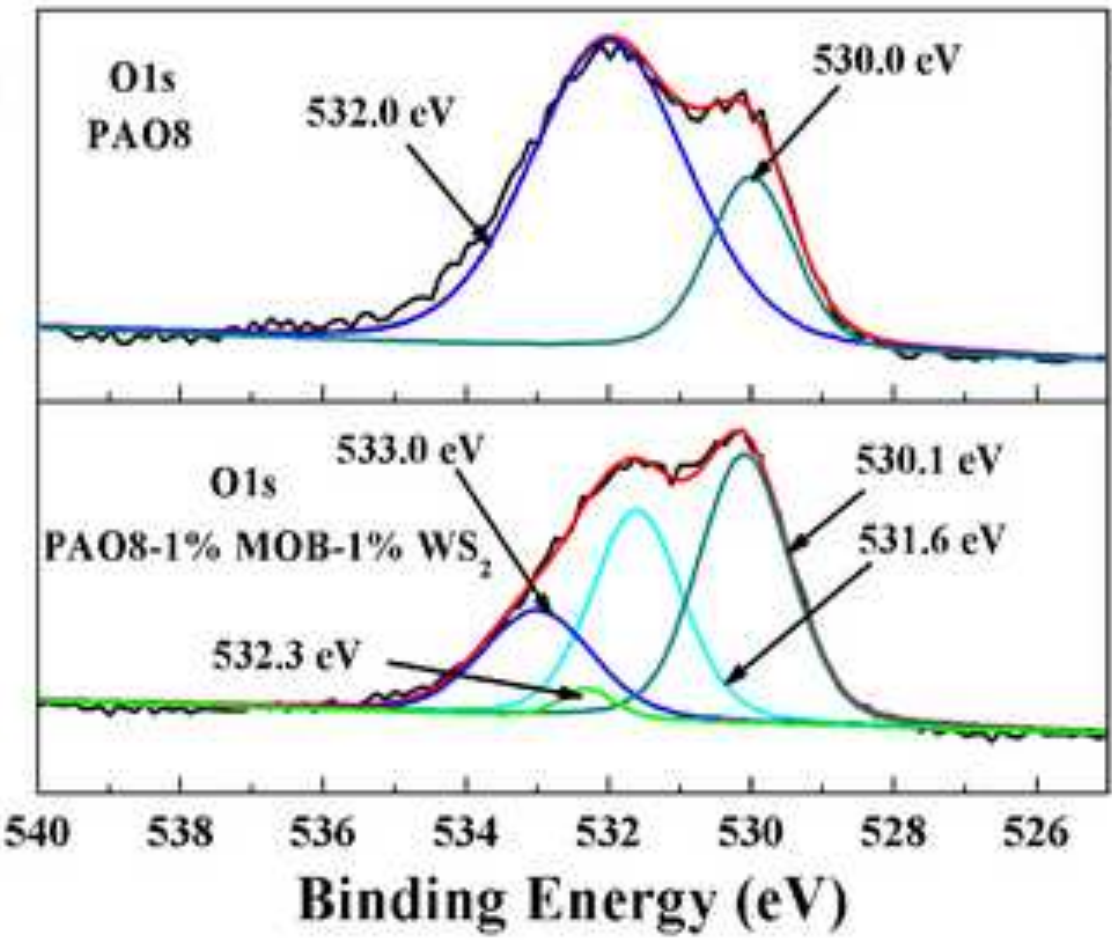

(b)

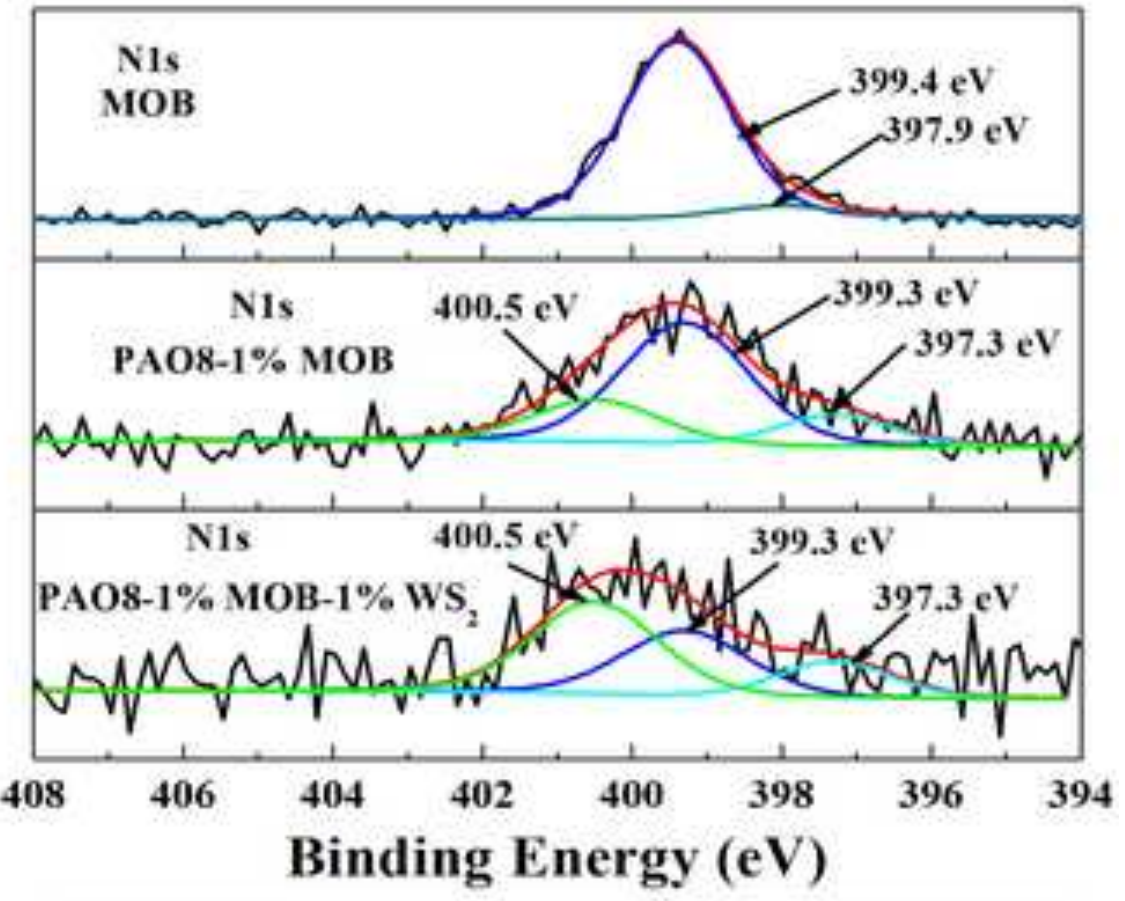

(d)

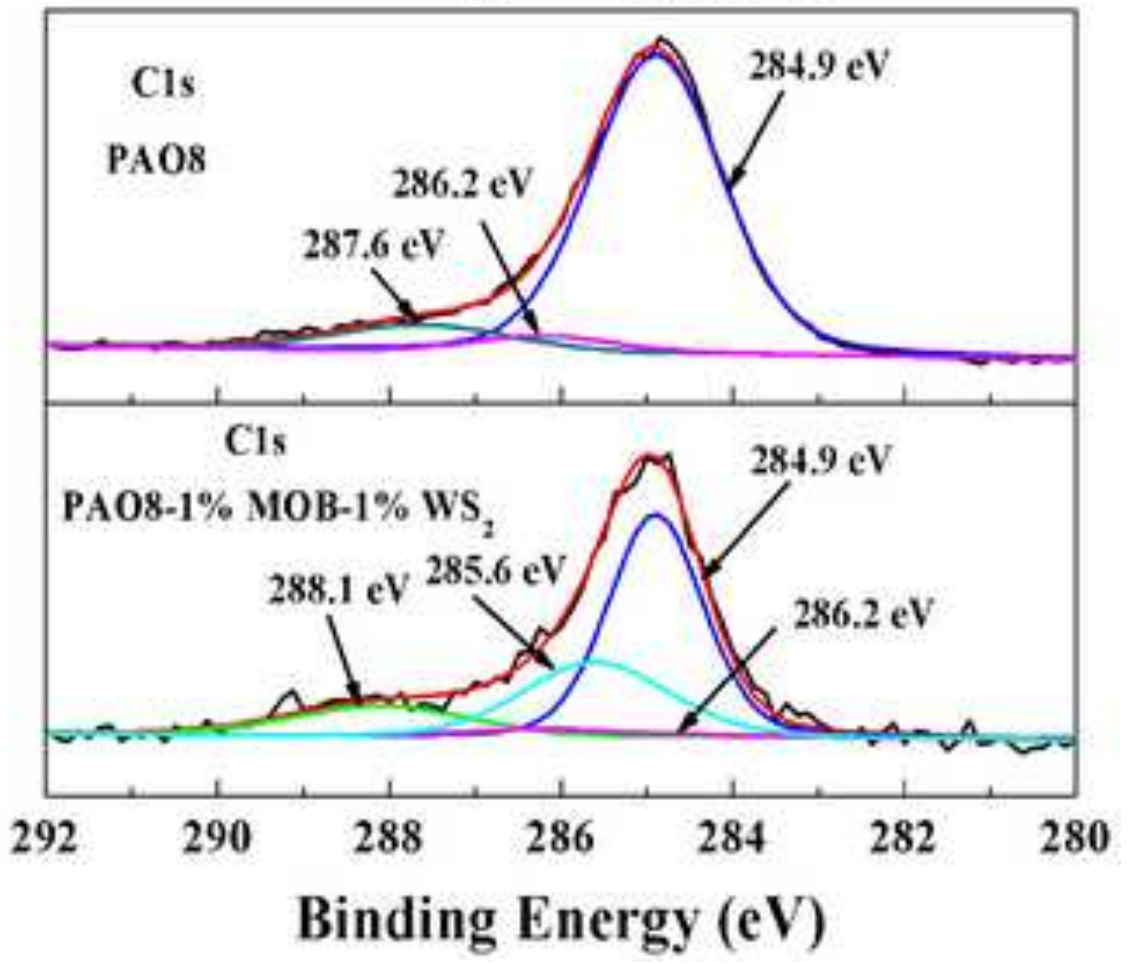




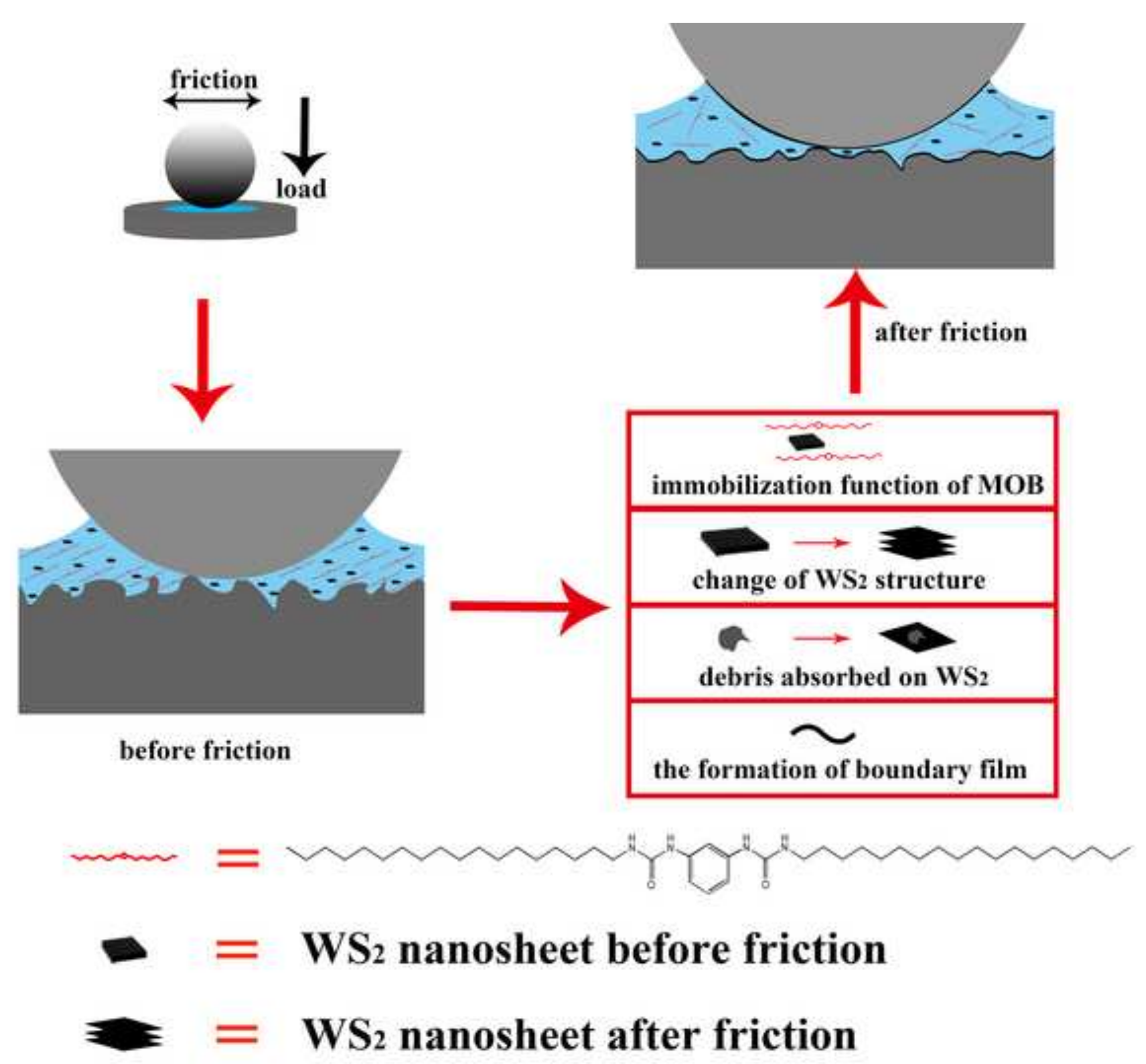


Table 1

\begin{tabular}{ccc}
\hline Vibration mode & IR $/ \mathrm{cm}^{-1}$ & Raman $/ \mathrm{cm}^{-1}$ \\
\hline N-H stretching vibration & $3305[17-18]$ & $3320[17]$ \\
$\mathrm{C}-\mathrm{H}$ stretch modes in phenyl group & $3119[19]$ & $3060[17]$ \\
$\mathrm{C}=\mathrm{O}$ stretch & $1634[17,20]$ & $1657[17,21]$ \\
$\mathrm{C}-\mathrm{C}$ stretch in alkyl & $1171[22]$ & $1132,1057[21]$ \\
$\mathrm{CH}_{2}$ deformation vibration & $1467[23]$ & $1440[21]$ \\
$\mathrm{CH}$ wagging & -- & $1292[27]$ \\
$\mathrm{CH}_{2}$ symmetrical stretching vibration & $3031[22]$ & $2850[27]$ \\
$\mathrm{CH}_{3}$ symmetrical stretching vibration & $2846[22]$ & $2884[27]$ \\
$\mathrm{CH}_{2}$ unsymmetrical stretching vibration & $2923[24]$ & $2927[27]$ \\
$\mathrm{CH}_{3}$ symmetrical deformation vibration & $1380[25-26]$ & $1380[18]$ \\
\hline
\end{tabular}


Table 2

\begin{tabular}{|c|c|c|c|}
\hline \multicolumn{2}{|r|}{ PAO8 } & \multicolumn{2}{|c|}{ PAO8-1\% MOB-1\% $\mathrm{WS}_{2}$} \\
\hline Frequency $/ \mathrm{cm}^{-1}$ & Corresponding compounds & Frequency $/ \mathrm{cm}^{-1}$ & Corresponding compounds \\
\hline 210 & $\alpha-\mathrm{Fe}_{2} \mathrm{O}_{3}[46-47]$ & $217,184,500$ & $\alpha-\mathrm{Fe}_{2} \mathrm{O}_{3}[46-47]$ \\
\hline 273 & $\alpha-\mathrm{Fe}_{2} \mathrm{O}_{3}[46-47]$ & 350,417 & $\mathrm{WS}_{2}[28]$ \\
\hline 386 & $\gamma$-FeOOH $[46,48]$ & 398 & S-C-C deformation vibration [50] \\
\hline 482 & $\alpha-\mathrm{FeOOH}[46]$ & 565 & Fe-N-O binding vibration [49] \\
\hline 586 & $\alpha-\mathrm{Fe}_{2} \mathrm{O}_{3}, \mathrm{Fe}-\mathrm{C}-\mathrm{O}[46-47,49]$ & 596 & Fe-NO stretching vibration [49] \\
\hline 645 & $\mathrm{Fe}_{3} \mathrm{O}_{4}[46]$ & 654 & $\mathrm{~S}-\mathrm{CH}_{2}$ stretching vibration [50] \\
\hline 1300 & $\gamma-\mathrm{FeOOH}[46,48]$ & 1290 & $\begin{array}{l}\text { C-N stretching vibration of } \\
\text { Aromatic amine [18] }\end{array}$ \\
\hline & & & $\mathrm{N}=\mathrm{N}$ stretching vibration of the \\
\hline 1340 & Carbonization [44-45] & 1410 & $\begin{array}{l}\text { azo compound conjugated to the } \\
\text { aromatic ring }[18]\end{array}$ \\
\hline 1575 & Carbonization [44-45] & 1503 & $\mathrm{NH}$ in-plane bending vibration [51] \\
\hline-- & -- & 1340,1575 & Carbonization [44-45] \\
\hline
\end{tabular}

